\title{
NueVOS RETOS EN EL TERCER PAÍS: MIGRACIONES Y GESTIONES ADMINISTRATIVAS DE LA FRONTERA COLOMBO-VENEZOLANA*
}

\author{
Sebastián Polo Alvis ${ }^{* *}$ \\ ENRIQUe SERrano López ${ }^{* * *}$ \\ Francelly Steffany Triana Barragán ${ }^{* * *}$
}

\section{Resumen}

A partir de una revisión de la actualidad de la realidad migratoria entre Colombia y Venezuela, este artículo pretende realizar un análisis sobre los diversos avances administrativos de la gestión fronteriza. A pesar de la gran importancia que han suscitado las mi- graciones venezolanas en Colombia a lo largo de los últimos cinco ańos, la comprensión de los elementos políticos, económicos y sociales de las condiciones internas de ambos países pueden dar luces de las lógicas correctas para la adecuada gestión administrativa de la frontera. Se espera que el lector, además de tener una visión sobre el estado de las migraciones

* La presente investigación se realizó en el marco del Semillero de Migraciones Colombianas al Exterior (sEmIcoex) de la Universidad del Rosario. Los autores agradecen a Ángela Mora, Ronal Rodríguez y a Juan Camilo Ito por su colaboración para la realización de este artículo.

** Politólogo, Universidad del Rosario. Profesor de Cátedra y coordinador del Semillero de Migraciones Colombianas al Exterior, Universidad del Rosario, Bogotá (Colombia). [sebastian.polo@urosario.edu.co].

*** Candidato a Doctor en Filosofía de la Universidad Javeriana; máster en Estudios de Asia y África, el Colegio de México, y máster en Análisis de problemas Políticos Económicos Internacionales, Universidad Externado y el IEP de París. Profesor de planta, Investigador y Director del Semillero de Migraciones Colombianas al Exterior, Facultad de Ciencia Política, Gobierno y Relaciones Internacionales, Universidad del Rosario, Bogotá (Colombia). [enriqueserrano3@gmail.com].

**** Internacionalista, Universidad del Rosario. Investigadora adjunta del Semillero de Migraciones Colombianas al Exterior, Universidad del Rosario, Bogotá (Colombia). [francelly.triana@urosario.edu.co].

Recibido: 24 de febrero de 2018 / Modificado: 31 de julio de 2018 / Aceptado: 1 de agosto de 2018.

Para citar este artículo

Polo Alvis, S., Serrano López, E. y Triana Barragán, F. (2018). Nuevos retos en el tercer país: migraciones y gestiones administrativas de la frontera colombo-venezolana. OpERA, 23, 27-57.

DOI: https://doi.org/10.18601/16578651.n23.04 
bilaterales entre Colombia y Venezuela, pueda tener una perspectiva más profunda sobre los retos a la gobernabilidad de la frontera colombo-venezolana.

Palabras clave: migraciones, Colombia, Venezuela, fronteras, América Latina.

\section{NEW CHALLENGES IN THE THIRD COUNTRY: MIGRATIONS AND ADMINISTRATIVE MANAGEMENT OF THE COLOMBO-VENEZUELAN BORDER}

\section{Abstract}

The purpose of the present work consists, from a review of the current reality of the migration situation between Colombia and Venezuela, to carry out an analysis of the various administrative advances of border management. Despite the great importance that Venezuelan migrations have aroused in Colombia over the past five years, understanding the various political, economic and social elements of the internal affairs of both countries can provide the basic elements for understanding the correct logic for the proper administrative management of the border. It is expected that the reader achieves with this paper, in addition to having a vision about the state of bilateral migrations between Colombia and Venezuela, develop a deeper perspective on the challenges to governance of the Colombian-Venezuelan border.

Key words: Migrations, Colombia, Venezuela, borders, Latin America.

\section{INTRODUCCIÓN}

A lo largo de la historia de las relaciones entre Colombia y Venezuela, el tema de las migraciones y el manejo fronterizo ha sido un agente determinante dentro de la agenda bilateral. Con la creciente influencia de las migraciones dentro de la toma de decisiones en materia económica, política, social y laboral, este fenómeno ha moldeado políticas autónomas de cada uno de los países para la coordinación de un mantenimiento del orden dentro de los flujos de entrada y de salida en cada país. Sin embargo, las migraciones también han servido de termómetro de las coyunturas internas y de las lógicas de las relaciones bilaterales.

Por tanto, el propósito del presente artículo es indagar sobre las tendencias migratorias actuales entre Colombia y Venezuela, además de realizar un análisis sobre los diversos avances administrativos del manejo migratorio que se deriven de este nuevo escenario. El progresivo deterioro del entorno económico y social en Venezuela, al igual que el turbulento proceso de construcción de paz en Colombia, plantean un escenario de creciente preocupación sobre el desarrollo de la problemática migratoria; fenómeno que también puede dar señales para la comprensión paralela de los procesos internos de ambos países y, a su vez, el inicio de una nueva perspectiva de gobernanza de la multiplicidad de elementos que complejizan el escenario fronterizo entre Colombia y Venezuela.

Metodológicamente, mediante análisis de resultados de datos censales y demográficos, el presente trabajo se basa un estudio histórico y estadístico de las migraciones entre 
ambos países en el marco de los últimos veinte años, siendo este un periodo de transición y diversificación en las tendencias migratorias colombianas, determinante para el desarrollo de los flujos migratorios de la tercera ola migratoria. A partir de este análisis, se busca revisar la implementación de las gestiones de las autoridades competentes, lo cual nos permite comprender la construcción de las capacidades de reacción para el manejo de la emergencia migratoria en el país. La presente investigación no solo se justifica por la actualidad del fenómeno migratorio, sino por la necesidad de comprender las lecturas que han desarrollado las entidades competentes en el manejo oportuno de la presente problemática.

\section{Historias entrelazadas: procesos paralelos, problemas perpendiculares}

A pesar del devenir de los procesos políticos y las problemáticas internas de cada país, las lógicas transfronterizas han incidido transversalmente en el contexto interno de Colombia y Venezuela. Sin embargo, a pesar de esta condición, la evolución política de ambos países ha sido relativamente independiente hasta hace poco. En el caso colombiano, como resultado de la violencia partidista de los años cuarenta y cincuenta, la cual tuvo su fin con los acuerdos pactados en Benidorm y Sitges en 1956 y 1957, se sellaría la formación de la coalición partidista del Frente Nacional conformada por el Partido Conservador y el Partido Liberal (Abel y Palacio, 1991, p. 207). El dominio político de esta coalición, en conjugación con diversos elementos derivados del surgimiento de guerrillas tras La Violencia
(1946-1956), propiciaría el escenario para el surgimiento de movimientos insurgentes de izquierda como las Fuerzas Armadas Revolucionarias de Colombia-Ejército del Pueblo (FARC-EP), el Ejército de Liberación Nacional (ELN), el Ejército Popular de Liberación (EPL), y luego el Movimiento 19 de Abril (M-19), que buscarían subvertir el orden político colombiano, para dar inicio a un conflicto que, a lo largo de los años posteriores, iría más allá de las fronteras nacionales.

Tras la aparición de estas guerrillas, si bien hubo sucesivos intentos de "pacificación" de estos movimientos desde el Estado colombiano, tal como el controversial Estatuto de Seguridad de 1978 creado durante la presidencia de Julio César Turbay Ayala (1978-1982), la Ley de Amnistía de 1982 y los Acuerdos de La Uribe en 1986 durante la presidencia de Belisario Betancur (1982-1986), el creciente auge del narcotráfico derivó en el surgimiento de carteles y posteriormente cuerpos paramilitares (Abel y Palacio, 1991, p. 240), quienes a su vez atacaron frontalmente a miembros y activistas políticos de izquierda como miembros y líderes políticos de la Unión Patriótica y del M-19. Estos incidentes, además del crecimiento acelerado del narcotráfico a lo largo de las décadas de los ochenta y noventa, impulsaron a movimientos como las FARC-EP y el ELN a buscar aumentar su poderío militar utilizando estos métodos ilegales de financiamiento para contrarrestar posibles ofensivas en detrimento de su vigencia; meta que se venía contemplando desde la creación de la Campańa Bolivariana por la Nueva Colombia, la cual es resultante de la Séptima Conferencia de las FARC-EP realizada en 1984. 
Durante la década de los noventa, el contexto político del país se caracterizó por un proceso de transformación de las lógicas de conflicto armado y de las redes de narcotráfico en el que, de acuerdo con Echandía (2000, p. 121):

Las acciones propias de la confrontación, como los contactos armados y los hostigamientos, así como los sabotajes a la infraestructura económica, aumentaron ostensiblemente en el conjunto de acciones armadas, mientras que las acciones típicas de financiamiento (asaltos a poblaciones, entidades y vehículos de transporte) disminuyeron. Estos cambios expresan la mayor capacidad militar con que cuentan hoy los grupos guerrilleros, en buena medida por haber logrado diversificar las prácticas de financiamiento que hoy dependen en alto grado del secuestro, de la extorsión y de las contribuciones forzadas del narcotráfico.

Con el recrudecimiento de la violencia, y el escalamiento del conflicto armado entre el Ejército Nacional de Colombia contra los movimientos insurgentes a lo ancho del territorio nacional durante los años noventa, tras el fracaso de los diálogos del Caguán en el 2002 iniciados desde la presidencia de Andrés Pastrana (1998-2002), se dio apertura a un proceso político y militar implementado desde los periodos presidenciales de Álvaro Uribe Vélez (2002-2010), enfocado en una neutralización de estas guerrillas en el ámbito militar y una reducción de la producción de narcóticos; dicho proceso estuvo apoyado por Estados Unidos con los fondos provenientes del Plan Colombia, el cual daría resultados en el plano militar. No obstante, como resultado de un proceso de negociación de cuatro años gestado por Juan Manuel Santos (2010-2018), en 2016 se firmaron los Acuerdos de Paz entre el Gobierno de Colombia y las FARC-EP, lo que abrió paso a una nueva fase de los procesos políticos relacionados con los grupos armados.

Por otro lado, durante la segunda mitad del siglo xx, Venezuela estaba atravesando por un periodo histórico sin precedentes. Como resultado de la transición a la democracia derivada del Pacto de Punto Fijo de 1958, tras la dictadura de Marcos Pérez Jiménez, la cual se consolidaría con la creación de la Constitución Nacional de 1961, Venezuela experimentaría un proceso de estabilidad política e institucional dentro de un entorno democrático sin igual en su historia, la cual se caracterizaba por una tendencia dominante del estamento militar a ser el agente político central durante la primera mitad del siglo xx. Acompañado por un auge económico impulsado por los altos precios del petróleo causados por los embargos realizados tras la guerra del Yom Kippur y de la Revolución iraní, en el que "el precio promedio de 1973 fue de US\$3,71 por barril, en 1974 pasó a US\$10,53 y siguió ascendiendo hasta US\$12,78 en 1978" (Arráiz, 2007, p. 179). Con la nacionalización de los procesos extractivos del petróleo y del hierro gestionados durante la primera presidencia de Carlos Andrés Pérez (1974-1979), mediante la creación de la empresa estatal Petróleos de Venezuela (PDVSA), el auge económico dio pie a la implementación de un Estado empresarial en el que se buscaba la creación y el subsidio delaindustria privada nacional, en detrimento de la importación y de la competencia; política 
que sería acompańada con el modelo de industrialización por sustitución de importaciones (ISI) gestado dentro del V Plan de la Nación.

Sin embargo, a pesar de las gestiones contracíclicas de la presidencia de Luis Herrera Campíns (1979-1984), el creciente endeudamiento del Estado venezolano causado por las grandes inversiones generadas por el sistema del Estado empresarial, además del aumento de los precios del petróleo provocado por la guerra entre Irán e Irak durante los primeros años de la década de los ochenta, impidió un manejo estable de la deuda externa que mantuvo Venezuela y derivó en un periodo de recesión económica. A pesar de los posteriores intentos de manejo de la deuda externa y del mantenimiento del IsI durante la presidencia de Jaime Lusinchi (1984-1989), no sería sino hasta la segunda presidencia de Carlos Andrés Pérez (1989-1993) cuando se haría una intervención directa a la crisis económica; acción que se caracterizaría por la suspensión del modelo IsI, la liberación de tasas de interés de las divisas, la privatización de empresas estatales y el aumento del precio de la gasolina, medidas encaminadas a "paliar la alta inflación en la economía nacional” (Arráiz, 2007). No obstante, junto con un panorama negativo de la población sobre la creciente corrupción de los funcionarios públicos, estas medidas causaron un fuerte descontento social que derivó en revueltas sociales como el Caracazo en 1989 , que reflejó un panorama de crisis de los partidos políticos, conjugado con una "crisis económica y un cataclismo social" (Ewell, 1991, p. 355).

Gracias a estas circunstancias, la amenaza de una toma del poder por parte del Ejército se manifestó en los intentos fallidos de Golpe de Estado en 1992, de los cuales uno fue liderado por el teniente coronel Hugo Chávez, quien llegaría a la presidencia en el año 1999. Con el ascenso de Chávez (1999-2013) y la redacción de la Constitución Nacional de 1999, se daría inicio a un profundo proceso de transformación política en búsqueda de un proyecto político socialista sustentado económicamente durante un periodo de alza de precios del petróleo, el cual pudo sostenerse hasta su muerte en 2013, a pesar de episodios internos como el paro petrolero de 2002, el intento de golpe de Estado durante el mismo año, y el referendo revocatorio de 2004. Sin embargo, a pesar de estos episodios de inestabilidad política, el progresivo avance del precio del petróleo generó condiciones económicas y sociales que propiciarían nuevos movimientos migratorios de entrada, conjugado con el inicio de la tercera ola migratoria colombiana marcada por un escenario derivado del fracaso de los diálogos del Caguán en el 2002, que daría pie a un escalamiento del conflicto.

Ahora bien, dentro de los múltiples factores que han condicionado las migraciones entre ambos países, el tema de la porosidad de la frontera colombo-venezolana es un agente de incidencia transversal. Además, dicho elemento repercute directamente en parte de las lógicas del conflicto armado en Colombia, además de la transformación del fenómeno del narcotráfico, del contrabando y de la creciente desconfianza política que se ha dado como resultado de los proyectos políticos divergentes que se desarrollaron en los escenarios internos de ambos países. 
Casos como la crisis diplomática de 2008 tras la Operación Fénix ${ }^{1}$, el impase de 2010 por la presencia de campamentos de las FARC-EP y del ELN en territorio venezolano, y la crisis de 2015, demuestran la condición turbulenta de las relaciones bilaterales durante los últimos años; asimismo, los mencionados casos demuestran una posible condición de vulnerabilidad acorde con los diversos elementos que se desprenden de los anteriores. La existencia de un entorno fronterizo difícil de escaso monitoreo, que es una ventana de oportunidad para la proliferación de diversas actividades criminales, conjugado con un escenario de crisis socioeconómica y una desarticulación interinstitucional en el control fronterizo y migratorio, crea un área gris de latente afectación negativa para el curso normal de las actividades cotidianas dentro de la zona.

En ese periodo de incidentes bilaterales, y como un hito de seria importancia para el desarrollo de este trabajo, la crisis del 2015 entre ambos países es un punto de inflexión. Tras el cierre fronterizo decretado por el presidente venezolano Nicolás Maduro (2013 hasta hoy), se implementa la activación del estado de excepción en los estados federales fronterizos de Zulia, Táchira, Apure y Amazonas, para restablecer el orden público por hipotéticas incursiones paramilitares en Venezuela desde territorio colombiano. Dicho estado de excepción provocó deportaciones masivas, sin previo aviso, de colombianos y personas con doble nacionalidad que residían en dicho país, en el que sus hogares fueron demolidos y su salida del país fue forzada.

Las migraciones transfronterizas entre Colombia y Venezuela se han ido desarrollando paralelamente con las dinámicas y transformaciones políticas, económicas y sociales de ambos países, en las que se han consolidado redes sociales de migrantes condicionadas por factores de atracción y expulsión contextuales, las cuales determinan e influyen en la realización de movimientos migratorios, ya sean de salida o de retorno. A partir de lo anterior, la presencia masiva de colombianos o venezolanos puede entenderse como un fenómeno que ha tomado cada vez más protagonismo, el cual se ha encuadrado dentro de las realidades específicas de las condiciones internas de cada país. No obstante, los escenarios de crisis económica, de persecución política hacia la oposición, y el deterioro de las condiciones de vida de los venezolanos bajo los últimos cinco años del régimen de Maduro, también han definido nuevos órdenes tendenciales dentro del historial migratorio de ambos países.

Por ende, es preciso preguntar, ¿cuáles pueden ser las implicaciones de estos fenómenos migratorios dentro de los panoramas políticos y económicos de Colombia y Venezuela? Para la respuesta adecuada a la anterior pregunta, en primer lugar es preciso identificar las condiciones actuales de las migraciones entre ambos países, y conocer el desarrollo de los procesos de regularización y control de tránsito de migrantes a través de la frontera

\footnotetext{
1 Como resultado de la incursión militar del Ejército Nacional de Colombia, en la provincia ecuatoriana de Sucumbíos, la cual resultó con la muerte del miembro del Estado Mayor Central de las FARC-EP, Raúl Reyes, y de otros 22 guerrilleros, el Gobierno venezolano reaccionó con la ruptura de relaciones diplomáticas con Colombia.
} 
colombo-venezolana. A partir de lo anterior, se pretende analizar la forma de incidencia de las migraciones regulares en el contexto político y social de cada país, como un factor determinante para las coyunturas bilaterales e internas de los casos presentados. Por último, se formularán las conclusiones pertinentes del presente trabajo, además de realizar observaciones sobre las tendencias migratorias entre ambos países y su rol en el desarrollo de posibles nuevas lógicas dentro de las relaciones bilaterales.

\section{LAS MIGRACIONES COLOMBIANAS HACIA VENEZUELA}

A lo largo de los últimos cincuenta ańos, la migración masiva de colombianos hacia Venezuela, inicialmente, se desarrolló acorde con el auge petrolero experimentado durante los años setenta. Pero, también dicha manifestación se explica por el deterioro de las condiciones de vida de los colombianos durante los ańos ochenta y noventa, resultantes de un panorama de crisis económica del sector agrario, de la violencia política y el terrorismo derivado de la guerra frontal del Estado contra el narcotráfico y la subversión. Durante los años de la "Venezuela saudita", este país se consolidó como "lugar de destino de migrantes regionales durante buena parte del siglo xx, operando como centro de un sistema migratorio regional que involucraba a los países vecinos" (oIM, 2012b, p. 15). A raíz del auge petrolero:

... la economía se ha expandido violentamente, pues de 14.000 millones de bolívares que tenía en 1974 de presupuesto anual, saltó a 42.000 millones de bolívares en 1976, lo cual provocó grandes inversiones en el área industrial. Estas fuertes inversiones han generado una violenta demanda de mano de obra especialmente calificada, que necesariamente tiene que reclutarse, parte de ella, en los mercados internacionales (Márquez y Mayesky, 1980, p. 14).

Desde Colombia, la migración hacia Venezuela durante la segunda mitad de la década de los setenta se enfocó inicialmente en la provisión de mano de obra agrícola "en áreas limítrofes, asociada a la emigración rural-urbana de la población local" (Mejía, 2012, p. 190), que luego también sería compuesta por profesionales y técnicos. Estos movimientos migratorios se desarrollaron "sobre todo desde la zona fronteriza y de los departamentos de la costa atlántica que, en su mayoría, se realizaron de una manera clandestina” (Márquez y Mayansky, 1980, pp. 13-14). Las migraciones hacia Venezuela durante este periodo se caracterizaron por experimentar un crecimiento exponencial, en el que se pasó de registrar 180.144 connacionales en 1971, a registrar la presencia de 441.831 colombianos en 1973 (Márquez y Mayansky, 1980) (figura 1); episodio que conformaría gran parte de lo que sería la segunda ola migratoria colombiana al exterior.

A pesar de la desaceleración económica durante los ańos ochenta, lo cual implicó un periodo de recesión, la migración colombiana mantuvo un ritmo constante de crecimiento, aunque también con un episodio de brusca desaceleración. Entre 1971 y 1973 se pasó de registrar un crecimiento del 145\% de la población colombiana en Venezuela, a un crecimiento porcentual del 15\% entre 1973 y 1981, año en el que se registró un total de 
508.166 connacionales radicados en este país (figura 1). Además, las dificultades económicas derivadas de la incapacidad de un manejo oportuno de la deuda externa provocaron la reducción del atractivo de Venezuela como destino de migración, lo cual repercutió en la prolongación de la ralentización del crecimiento de la población colombiana residente hasta comienzos de los ańos noventa, época en la que la cifra de connacionales ascendía a 528.924 personas, es decir, un crecimiento porcentual de apenas un $4 \%$ en un lapso de 10 ańos, el más bajo de la historia de las migraciones colombianas hacia Venezuela.

A pesar de los esfuerzos realizados durante la presidencia de Rafael Caldera (1994-1999) por mejorar la situación económica del país vecino, dentro de los cuales se destacan políticas como la implementación de la Agenda Venezuela y el proceso de apertura petrolera en la explotación de la faja del Orinoco (Arráiz, 2007), que derivaron en una mejoría temporal que terminaría con el desplome de los precios del petróleo y la crisis económica de 1999, la población colombiana en Venezuela comenzó a experimentar un crecimiento mayor: para 1999, que fue el peor año de la crisis económica de fin de siglo, se registró la salida de 224 mil personas; entre 1996 y 2005, el flujo neto promedio de colombianos hacia el exterior fue de 174 mil personas al año (Cárdenas y Mejía, 2006, pp. 6-7).

Con la proliferación de la violencia generalizada, el fortalecimiento militar de las FARC-EP durante los ańos noventa y la progresiva crisis política experimentada durante esa década, además de las consecuencias económicas derivadas de la crisis económica de 1999 y del terremoto de Armenia, se gestó la manifestación de una tercera ola migratoria que se daría a inicios de la década del 2000. Según Mauricio Palma (2015, p. 11), el inicio de esta tercera ola migratoria se derivó de "la percepción de inseguridad producida por el conflicto armado y sus elementos conexos", los cuales "se han convertido en principios que constriñen las actividades y expectativas de migrantes prospectivos", en conjugación con el deterioro económico y social experimentado a lo largo de la década de los noventa.

Aterrizado al caso de las migraciones colombianas a Venezuela, el crecimiento de esta población comenzaría a volver a experimentar un aumento considerable durante este periodo, en el que, para los registros del año 2001, esta población alcanzaría la cifra de 609.196 personas, lo cual refleja un incremento porcentual del $15 \%$ en comparación con la cifra del Censo de 1990 (figura 1). Sin embargo, el crecimiento no se detendría allí. Con la llegada de Hugo Chávez al poder, al igual que el posterior crecimiento vertiginoso del precio del petróleo a mediados de la década del 2000, se dio inicio a la implementación de un proyecto político socialista basado en la aplicación de políticas de asistencia social, tanto en la provisión de productos de la canasta familiar, como en temas de protección laboral y provisión de educación pública. Estos incentivos, posiblemente, derivarían en el progresivo aumento de la población migrante de nacionalidad colombiana en Venezuela. De acuerdo con Cárdenas y Mejía (2006, p. 6), dicho aceleramiento general de la diáspora colombiana "se atribuye principalmente a dos factores, la crisis económica de fin de siglo y a la intensificación del conflicto armado". 
FIGURA 1. EVOLUCIÓN HISTÓRICA DE LA POBLACIÓN COLOMBIANA EN VENEZUELA, 1951-2015

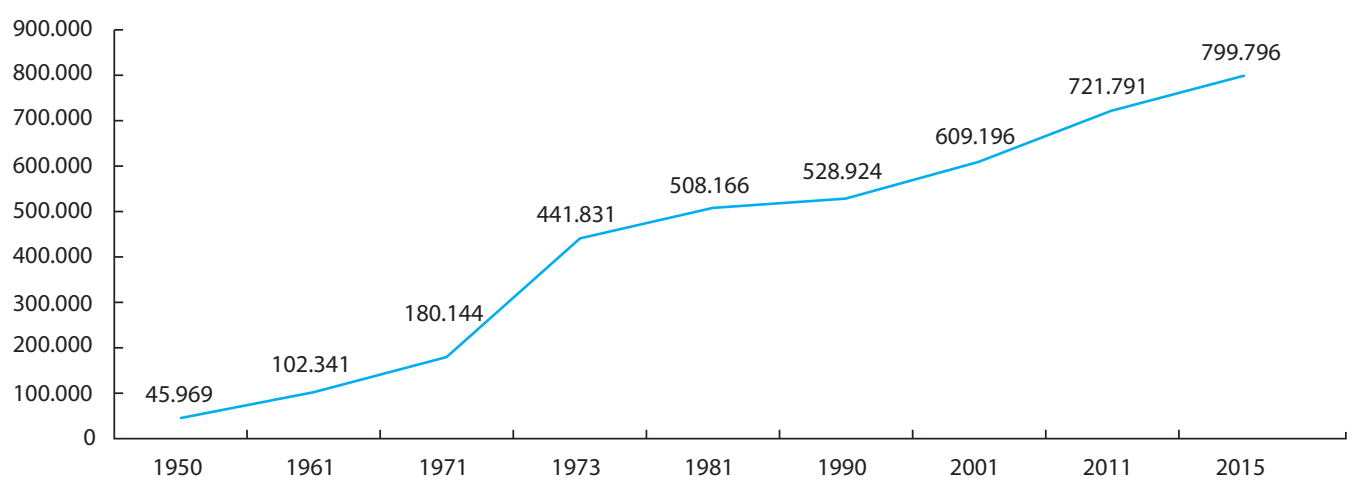

Fuente: elaboración propia basada en información de Márquez y Mayansky (1980), DANE (1973), información censal del Instituto Nacional de Estadística de los años 1990, 2001 y 2011, compilada por el Proyecto IMILA-Celade de la CEPAL (2016), y de la Organización de las Naciones Unidas para 2015 (2017).

Acorde con ello, entre los años 2000 y 2011 se registra un saldo total de 721.791 connacionales residentes en Venezuela (figura 1 y tabla 1), lo cual puede atribuirse al progresivo crecimiento del atractivo de Venezuela como destino migratorio por los grandes réditos económicos percibidos por los altos precios del petróleo entre 2005 y 2012 que, a su vez, eran invertidos en programas sociales de diversa índole de los que podían ser beneficiarios; condiciones que se darían a pesar de la presencia de periodos de distanciamiento diplomático entre ambos países ${ }^{2}$.

Sin embargo, es necesario hacer algunas salvedades antes de estudiar las dimensiones y realidades económicas de la diáspora colombiana durante los últimos quince años. Como se ha mencionado, las posibilidades de existencia de un escenario de subregistro poblacional de la diáspora colombiana están presentes, lo cual impide tener una visión proporcional del tamaño real de dicha población. Un ejemplo de ello se da en los procesos de regularización de los migrantes no documentados desarrollados a inicios de la década del 2000. De acuerdo con el trabajo de seguimiento realizado por el Grupo Académico Colombia-Venezuela (2015) sobre los flujos migratorios de colombianos hacia Venezuela, uno de los registros más recientes de aplicación de este tipo de políticas se remonta a los inicios de la presidencia de Hugo Chávez.

Con el lanzamiento del Plan Nacional de Regularización y Naturalización de Extranjeros y Extranjeras en 2004, las autoridades venezolanas declararon que "calculaban en 1.500 .000 los extranjeros indocumentados por lo que, al terminarlo, quedaban 800 mil sin resolver su situación, de los cuales estimaba que 680

\footnotetext{
2 "Luego de haber rondado los veinte dólares por barril entre 1999 y 2004, y llegado incluso la cesta venezolana a ser cotizada en ocho dólares por barril en febrero de 1999, desde 2005 el precio del petróleo muestra un desempeño ascendente que se mantiene hasta mediados de 2008, cuando su volatilidad característica se tradujo en diferenciales de más de cien dólares para un mismo tipo de crudo a lo largo del año” (Scrofina, 2012).
} 
TABLA 1. PERSONAS NACIDAS EN COLOMBIA RESIDENTES EN VENEZUELA POR AÑO DE LLEGADA, 2011

\begin{tabular}{|c|c|c|c|c|c|c|c|c|}
\hline Año de & $1950-1959$ & $1960-1969$ & $1970-1979$ & $1980-1989$ & $1990-1999$ & $\mathbf{2 0 0 0 - 2 0 1 1}$ & No disponible & Total \\
\cline { 2 - 9 } \\
Llegada & 30.736 & 56.339 & 157.981 & 122.415 & 100.873 & 223.528 & 25.919 & 721.791 \\
\hline
\end{tabular}

Fuente: elaboración propia basada en información censal del Instituto Nacional de Estadística, compilada por el proyecto IMILA-Celade de la CEPAL (2016).

mil eran colombianos" (Grupo Académico Colombia-Venezuela, 2015, p. 6). Sin embargo, es necesario considerar la dificultad de un panorama estadístico claro sobre este asunto, dando cabida a un posible caso de subregistro de poblaciones sin registrarse como migrantes regulares. Según el Alto Comisionado de las Naciones Unidas para los Refugiados (ACNUR) (2016a) (tabla 2), para 2014 se registró la presencia de 173.519 personas refugiadas o en condiciones similares al refugio ${ }^{3}$ provenientes de Colombia. Incluso, de acuerdo con la misma institución (2016b), se registra solamente la presencia de un total de 5.647 personas con estatus de refugiados. Por tanto, debido al gran tamaño de la población en situaciones similares a las condiciones de refugio, no hay una precisión sobre el registro de las personas mencionadas, lo cual puede causar una distorsión de los referentes estadísticos sobre la diáspora. Sin embargo, cabe mencionar que, a pesar de este inconveniente, es posible evidenciar que entre 2002 y 2014, el número de solicitudes ha disminuido notablemente, lo cual se puede atribuir, tanto a una reducción de los daños colaterales del conflicto armado en Colombia como a las consecuencias negativas de la crisis económica y política de Venezuela sobre temas migratorios. Esta posible hipótesis puede compartir las tendencias migratorias de la población regular, ya que a pesar de la particularidad de su condición migratoria, las condiciones coyunturales dibujan un panorama al que se enfrenta la población en general.

Ahora bien, la diáspora colombiana en Venezuela en los últimos veinte años se ha caracterizado por tener una alta representación porcentual respecto al total de la población extranjera en este país, consolidándose como la más populosa. Para 1990, los colombianos representaban el 51,6\% del total de la población extranjera, proporción que aumentaría a lo largo de los años en que, según los registros censales posteriores, alcanzaría a representar el $59,9 \%$ para 2001 , y el $70 \%$ para 2011 (tabla 3), lo cual demuestra que el crecimiento de esta población a lo largo de los últimos años no solo ha sido nominal, sino también en su representación porcentual.

Según datos del Instituto Nacional de Estadística (2014) (mapa 1), la distribución territorial de la diáspora colombiana en Venezuela se ha caracterizado por ubicarse en zonas de frontera, lo cual evidencia la continuación

\footnotetext{
3 De acuerdo con la definición oficial de ACNUR (2016a), la subcategoría "persona en condiciones similares al refugio" tiene un carácter descriptivo e incluye grupos de personas que se encuentran fuera de su país o territorio de origen y que enfrentan riesgos de protección similares a los de los refugiados, pero para los que no se ha determinado el estatuto de refugiado por razones prácticas o de otro tipo.
} 
TABLA 2. EVOLUCIÓN DEL NÚMERO DE REFUGIADOS PROVENIENTES DE COLOMBIA RESIDENTES EN VENEZUELA, 2002-2017

\begin{tabular}{|c|c|c|c|c|c|c|c|c|}
\hline & 2002 & 2003 & 2004 & 2005 & 2006 & 2007 & 2008 & 2009 \\
\hline Refugiados & 21 & 21 & 199 & 358 & 660 & 200.843 & 201.094 & 201.244 \\
\hline $\begin{array}{l}\text { Solicitantes de } \\
\text { asilo }\end{array}$ & 1.008 & 2.270 & 3.877 & 5.862 & 7.660 & 9.490 & 11.799 & 14.223 \\
\hline Otros & 50.000 & 26.192 & 26.359 & 200.001 & 200.000 & - & - & 17 \\
\hline \multirow[t]{2}{*}{ Total } & 51.029 & 28.483 & 30.435 & 206.221 & 208.320 & 210.333 & 212.893 & 215.484 \\
\hline & 2010 & 2011 & 2012 & 2013 & 2014 & 2015 & 2016 & 2017 \\
\hline Refugiados & 201.467 & 201.941 & 203.563 & 204.259 & 173.519 & 173.673 & - & 122.677 \\
\hline $\begin{array}{l}\text { Solicitantes de } \\
\text { asilo }\end{array}$ & 15.694 & 17.192 & 750 & 909 & 251 & 57 & - & 904 \\
\hline Otros & - & - & - & - & - & 1.765 & - & - \\
\hline Total & 217.161 & 219.133 & 204.313 & 205.168 & 173.770 & 175.495 & - & 123.581 \\
\hline
\end{tabular}

Fuente: elaboración propia basada en información de ACNUR (2018).

de las tendencias de comunicación transfronteriza de los colombianos residentes en este país. Se destaca la presencia de colombianos en los estados federales de Zulia (193.045), Táchira (138.952), Miranda (98.769) y Carabobo (49.133), además de contar con una presencia relevante en el Distrito Capital (55.650), y en los estados de Lara (33.879), Barinas (31.045), Aragua (21.539), Bolívar (14.639) y Apure (13.696).

Dentro de los elementos que valdría la pena resaltar en el caso de los colombianos en Venezuela, se destaca el índice de actividad económica de la población. Aunque el crecimiento nominal del número de colombianos en Venezuela ha sido de gran relevancia, el índice de inactividad ha sido proporcional a esta tendencia, en la que se pasó de registrar un $38,7 \%$ de inactivos del total de colombianos para 1990, a registrar un incremento a 48,4\% para 2011 (tabla 4). Sin embargo, es necesario mencionar que, como resultado del deterioro de las condiciones de vida derivadas de la crónica crisis económica y política por la que está atravesando el vecino país, las lógicas migratorias están experimentando un nuevo episodio de ralentización y regreso. Para poder revisar las evidencias de que el fenómeno mencionado está sucediendo, es necesario indagar sobre la evolución de dos referentes variables que nos pueden dar luces acerca de la dinámica de estas tendencias migratorias: la evolución de flujos migratorios y la evolución de remesas.

Por un lado, dentro de los flujos migratorios de colombianos hacia Venezuela (tabla 5) se han realizado 271.647 salidas de colombianos que declararon residir en el exterior entre 2007 y 2015. En dicho periodo se registraron picos en el ańo 2012, con 45.183 movimientos hacia Venezuela llevados a cabo por personas 
TABLA 3. EVOLUCIÓN DEL NÚMERO DE EXTRANJEROS EN VENEZUELA POR PAís DE NACIMIENTO, 1990-2011

\begin{tabular}{|c|c|c|c|c|c|}
\hline Total Censo 1990 & $1^{\prime} 024.121$ & Total Censo 2001 & $1^{\prime} 015.538$ & Total Censo 2011 & $1^{\prime} 031.103$ \\
\hline Colombia & 528.893 & Colombia & 609.196 & Colombia & 721.791 \\
\hline España & 104.088 & España & 76.648 & España & 46.463 \\
\hline Portugal & 68.105 & Portugal & 53.477 & Portugal & 37.326 \\
\hline Italia & 61.352 & Italia & 49.337 & Perú & 32.144 \\
\hline Perú & 27.748 & Perú & 35.871 & Italia & 30.840 \\
\hline Ecuador & 23.370 & Ecuador & 28.625 & Ecuador & 25.012 \\
\hline Chile & 20.787 & Chile & 15.530 & Cuba & 20.991 \\
\hline $\begin{array}{l}\text { República } \\
\text { Dominicana }\end{array}$ & 17.140 & $\begin{array}{l}\text { República } \\
\text { Dominicana }\end{array}$ & 14.332 & RP de China & 15.456 \\
\hline Siria & 12.809 & Siria & 13.194 & Chile & 12.037 \\
\hline Estados Unidos & 10.716 & Estados Unidos & 10.028 & $\begin{array}{l}\text { República } \\
\text { Dominicana }\end{array}$ & 11.399 \\
\hline Cuba & 10.157 & RP de China & 9.854 & Argentina & 7.736 \\
\hline Argentina & 9.070 & Cuba & 9.795 & Estados Unidos & 7.725 \\
\hline
\end{tabular}

Fuente: elaboración propia basada en información censal del Instituto Nacional de Estadística, compilada por el proyecto IMILA - Celade de la CEPAL (2016).

con la caracterización mencionada; cifra que posteriormente se reduciría en un $31 \%$ en comparación con los registros de 2015.

A pesar de que es una cifra que demuestra un notable decrecimiento de los flujos migratorios hacia Venezuela durante los últimos cuatro años, la ralentización del crecimiento de la migración colombiana en este país se puede evidenciar en una mayor proporción en los flujos migratorios por conceptos laborales. En detrimento del sorprendente incremento de los movimientos migratorios por concepto de estudios entre 2011 y 2015, el escenario en las migraciones por conceptos laborales es diametralmente opuesto, ya que se registra un desplome acelerado, en el que se pasó de 34.947 flujos realizados en el 2007, a tan solo
5.843 para el 2015. Este decrecimiento refleja el bajo incentivo económico de migrantes laborales colombianos a desempeñar funciones y actividades económicas en un país con una economía en crisis, con una inflación rampante y una falta de garantías a la propiedad privada, entre otros vejámenes, que son factores que inciden directamente en una caída en picada del atractivo de Venezuela como destino de migración laboral.

Por otro lado, durante los últimos once años, las remesas enviadas desde Venezuela se han caracterizado por ser uno de los focos de ingresos de divisas más importantes de la economía colombiana. En este contexto, y dadas las progresivas restricciones económicas que siguieron luego del gran periodo de bonanza 
TABLA 4. PERSONAS NACIDAS EN COLOMBIA QUE RESIDEN EN VENEZUELA, POR SEXO, ESTADO CIVIL Y CONDICIÓN DE ACTIVIDAD E INACTIVIDAD, 1990-2011

\begin{tabular}{|c|c|c|c|c|c|c|c|c|c|}
\hline Colombia & \multicolumn{3}{|c|}{1990} & \multicolumn{3}{|c|}{2001} & \multicolumn{3}{|c|}{2011} \\
\hline & \multicolumn{3}{|c|}{528.893} & \multicolumn{3}{|c|}{609.196} & \multicolumn{3}{|c|}{721.791} \\
\hline \multirow[t]{2}{*}{ Sexo } & \multicolumn{2}{|c|}{ Hombres } & Mujeres & \multicolumn{2}{|c|}{ Hombres } & Mujeres & \multicolumn{2}{|c|}{ Hombres } & Mujeres \\
\hline & \multicolumn{2}{|c|}{247.725} & 247.725 & \multicolumn{2}{|c|}{290.985} & 318.211 & \multicolumn{2}{|c|}{349.459} & 372.332 \\
\hline Estado Civil (+15) & Total & Hombres & Mujeres & Total & Hombres & Mujeres & Total & Hombre & Mujeres \\
\hline Solteros & 133.093 & 70.683 & 62.410 & 123.474 & 67.080 & 56.394 & 171.329 & 89.96 & 81.362 \\
\hline $\begin{array}{l}\text { Casados y en } \\
\text { unión libre }\end{array}$ & 311.086 & 150.606 & 160.480 & 384.175 & 192.870 & 191.305 & 422.181 & 213.11 & 209.062 \\
\hline Otros & 50.692 & 9.900 & 40.792 & 74.557 & 17.506 & 57.051 & 78.425 & 20.69 & 57.731 \\
\hline $\begin{array}{c}\text { Condición de } \\
\text { actividad (+15) }\end{array}$ & Total & Hombres & Mujeres & Total & Hombres & Mujeres & Total & Hombre & Mujeres \\
\hline Activos & 324.287 & 210.911 & 113.376 & 380.460 & 246.438 & 134.022 & 336.102 & 231.76 & 104.337 \\
\hline Inactivos & 183.412 & 26.650 & 156.762 & 211.265 & 35.849 & 175.416 & 349.251 & 98.88 & 250.368 \\
\hline Inactivos & Total & Hombres & Mujeres & Total & Hombres & Mujeres & Total & Hombre & Mujeres \\
\hline Ama de casa & 130.828 & 1.534 & 129.294 & 156.754 & 3.418 & 153.336 & - & & - \\
\hline Estudiante & 22.516 & 9.720 & 12.796 & 12.704 & 5.570 & 7.134 & - & & - \\
\hline $\begin{array}{l}\text { Jubilado o pensio- } \\
\text { nado }\end{array}$ & 2.189 & 1.259 & 930 & 3.881 & 2.241 & 1.640 & - & & - \\
\hline Otros & 27.879 & 14.137 & 13.742 & 37.926 & 24.620 & 13.306 & - & & - \\
\hline
\end{tabular}

Fuente: elaboración propia basada en información censal del Instituto Nacional de Estadística, compilada por el proyecto IMILA - Celade de la CEPAL (2016).

TABLA 5. FLUJOS MIGRATORIOS DE SALIDA DE COLOMBIANOS HACIA VENEZUELA POR RESIDENCIA EN EL EXTERIOR, MOTIVOS DE ESTUDIO Y MOTIVOS LABORALES, 2007-2015

\begin{tabular}{|l|c|c|c|c|c|c|c|c|c|c|}
\hline & 2007 & 2008 & 2009 & 2010 & 2011 & 2012 & 2013 & 2014 & 2015 & Total \\
\hline $\begin{array}{l}\text { Colombianos } \\
\text { con país de } \\
\text { residencia en } \\
\text { el exterior }\end{array}$ & 19.087 & 25.749 & 19.516 & 20.069 & 29.502 & 45.183 & 41.547 & 39.740 & 31.254 & 271.647 \\
\hline $\begin{array}{l}\text { Colombianos } \\
\text { por motivos } \\
\text { de estudio }\end{array}$ & 5.696 & 7.002 & 2.454 & 3.283 & 4.371 & 8.075 & 10.309 & 7.582 & 10.313 & 59.085 \\
\hline $\begin{array}{l}\text { Colombianos } \\
\text { por motivos } \\
\text { laborales }\end{array}$ & 34.947 & 33.876 & 24.107 & 18.592 & 17.299 & 19.669 & 13.272 & 7.619 & 5.843 & 175.224 \\
\hline
\end{tabular}

Fuente: elaboración propia basada en información otorgada por la Unidad Administrativa Especial Migración Colombia, vía derecho de petición, otorgada el 20 de noviembre de 2015. 
petrolera entre 2006 y 2013, el panorama sobre las remesas refleja el mismo fenómeno de las migraciones laborales. Según cifras del Banco de la República (2016) (figura 2), en un periodo de dos años se pasó de registrar un ingreso de 492 millones de dólares en remesas provenientes desde Venezuela, a registrar solamente 2,6 millones de dólares para 2015. Los anteriores elementos demuestran que, si bien la importancia de Venezuela como un destino tradicional de migración para Colombia mantiene vigencia, los recientes sucesos económicos y políticos han provocado un progresivo escenario de reducción del caudal migratorio e, incluso, la generación de un proceso de retorno.

De lo anterior es posible deducir que las migraciones colombianas hacia Venezuela se desarrollaron acorde con el crecimiento económico experimentado durante los ańos setenta impulsado por el auge petrolero, pero también por el deterioro de las condiciones de vida de los colombianos durante los años ochenta y noventa, resultantes de un panorama de crisis económica, violencia política y el terrorismo derivado de la guerra frontal del Estado contra el narcotráfico y la subversión. Además, con la proliferación de la violencia generalizada tras el recrudecimiento de los combates entre las fuerzas del Estado colombiano y los grupos subversivos, se gestó una tercera ola migratoria que se daría a inicios de la década del 2000, dentro de la cual gran parte de la diáspora migró hacia Venezuela incentivada por la instauración de políticas sociales y generación de subsidios económicos desde la administración de Hugo Chávez; migración que se vería reflejada en el incremento de dicha población registrado en el xiv Censo Nacional de Población y Vivienda. A partir de lo anterior, y con relación a las condiciones propias de la región fronteriza colombo-venezolana en temas de seguridad y cooperación bilateral, Irene Cabrera afirma:

Bajo este panorama, los gobiernos vecinos de Colombia se caracterizaron en un momento por prestar poca atención a la evolución del conflicto en las fronteras - de hecho, cabe mencionar que el Gobierno colombiano

FIGURA 2. EVOLUCIÓN DE LAS REMESAS ENVIADAS DESDE VENEZUELA HACIA COLOMBIA REPRESENTADAS EN MILLONES DE DÓLARES, 2005-2015

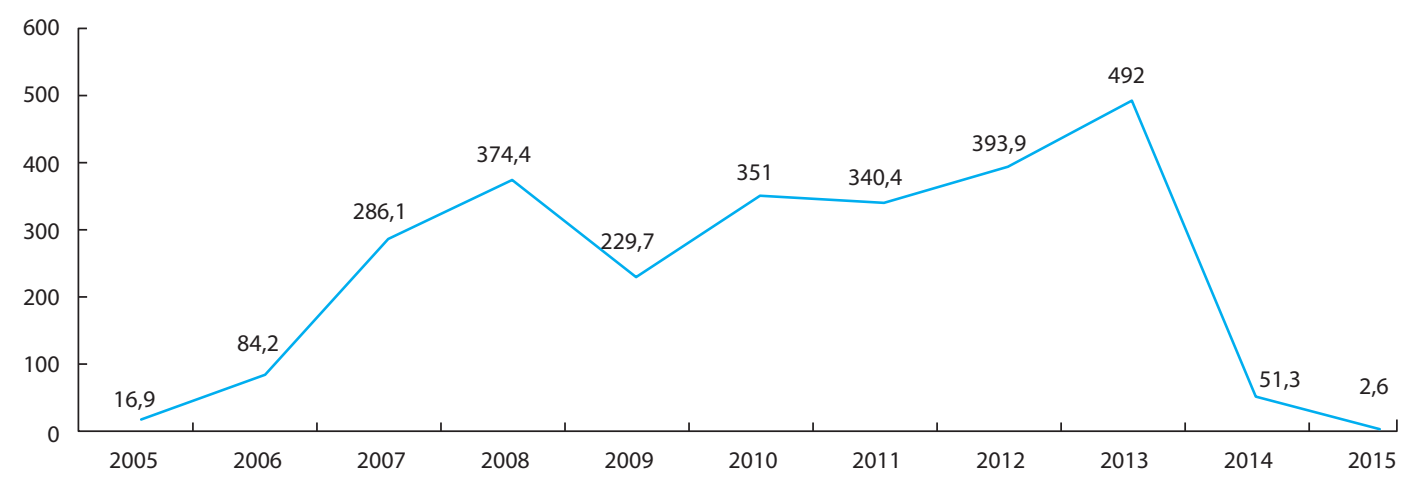

Fuente: elaboración propia basada en información del Banco de la República (2016). 
denunció cierta empatía y permisibilidad del Gobierno venezolano con los grupos guerrilleros en su territorio-. Ello se convirtió en un catalizador de las actividades militares y criminales sobre los espacios limítrofes sin que necesariamente existiera complicidad por parte de los gobiernos vecinos. Sin embargo, luego del episodio del bombardeo en territorio ecuatoriano se produjo un cambio significativo en las disposiciones de seguridad de algunos países de la subregión [...] A pesar de la disposición de los vecinos, los grupos irregulares siguen aprovechando la poca movilidad y las limitaciones en inteligencia para seguir realizando acciones armadas en la frontera y garantizar su supervivencia (2011, p. 23).

En conclusión, tras la revisión de las lógicas migratorias y fronterizas expuestas anteriormente, a pesar de que la diáspora colombiana en Venezuela en los últimos veinte años se ha caracterizado por ser dominante en la representación porcentual del total de la población extranjera en este país, las condiciones de crisis económica y política han incidido directamente en el decrecimiento de las migraciones hacia este destino -tanto laborales como estudiantiles-, como en su distribución territorial y volumen de envío de remesas.

\section{LAS MIGRACIONES VENEZOLANAS HACIA COLOMBIA}

Venezuela está atravesando por un momento histórico sin precedentes a nivel migratorio. A lo largo de su vida republicana no se había experimentado una emigración de personas de las proporciones registradas durante los últimos diez ańos. Históricamente, Venezuela se consolidó como un país receptor de migrantes provenientes de Europa y de otras regiones de América Latina en el que, a lo largo del siglo XIX, recibió la llegada de alemanes, españoles y portugueses gracias a su éxito agrícola en la producción de cacao y café (Deas, 1991, p. 178). No obstante, la entrada masiva de migrantes se percibiría al final de la Segunda Guerra Mundial; el creciente auge petrolero aumentaría el atractivo de Venezuela como destino migratorio de europeos, norteamericanos y colombianos. De acuerdo con Judith Ewell (1991, p. 320), las condiciones migratorias en Venezuela se configurarían directamente por el avance del sector petrolero en el país:

Después de 1945, llegó a Venezuela una avalancha de italianos, espańoles y portugueses (además de ciudadanos de la vecina Colombia), y el porcentaje de extranjeros pasó del 1,3 por 100 de la población en 1941 al 7 por 100 en 1961. La mayoría de ellos, como era de esperar, se estableció en las ciudades, principalmente en Caracas y encontró empleo en la construcción, el comercio y los servicios. Algunos de los más afortunados trajeron capital consigo, o lo obtuvieron rápidamente, y compraron sus propios negocios. Bajo la dictadura de Pérez Jiménez, unos cuantos contratistas de obras extranjeros se hicieron fabulosamente ricos. Los ciudadanos estadounidenses, aunque nunca fueron significativos desde el punto de vista numérico, se hicieron más visibles al abandonar los campos de petróleo para trasladarse a las ciudades con la intención de aprovechar las nuevas oportunidades que se ofrecían a su capital y sus servicios.

A partir del posterior auge petrolero experimentado en los años setenta, en el que hubo una alta recepción de migrantes colombianos anteriormente estudiada, Venezuela también se 
fue posicionando como un destino de recepción de exiliados y disidentes políticos provenientes del Cono Sur. No obstante, a pesar del registro de 1'024.121 extranjeros que residían en el territorio para 1990, al punto de llegar a la cifra histórica de 1'156.578 para 2011 (Comisión Económica para América Latina, 2016), por primera vez se está revirtiendo la tendencia migratoria histórica de Venezuela con la creciente salida de venezolanos durante los últimos diez años.

De acuerdo con registros de Naciones Unidas (2017), la evolución del número de venezolanos residentes en el extranjero ha crecido progresivamente durante los últimos treinta años, cuando se ha pasado de 185.282 venezolanos en el extranjero para 1990, al registro de 606.344 para 2015 y 357.439 para 2017 (figura 3). En Colombia, las migraciones venezolanas durante los últimos treinta ańos han sido de proporciones modestas. Acorde con los registros de Naciones Unidas (2017), para 1990 había 33.123 venezolanos residentes en Colombia. A partir de dicho registro, el crecimiento de esta población tendió a crecer de forma ralentizada; así, en el año 2000 pasó a 37.200, y para 2015 se percibió la presencia de 46.614. En términos porcentuales, la población venezolana en Colombia solo incrementó sus dimensiones en un $40 \%$ dentro de un lapso de 25 años (tabla 6).

No obstante, el progresivo deterioro de las condiciones de vida en Venezuela, al igual que la presencia de realidades coyunturales que pueden distorsionar la revisión estadística tales como la porosidad fronteriza, los sistemas de registro migratorio débiles en los diversos complejos fronterizos venezolanos, la irregularidad migratoria, entre otros, pueden distanciar las cifras anteriormente expuestas de una realidad plausible. Por ejemplo, hay estimaciones de la salida de más de 4’091.717 de venezolanos al exterior (Consultores 21, 2017), de las cuales se estimó la presencia de 550.000 por parte de las autoridades migratorias colombianas (El Tiempo, 2018). Sin embargo, la dimensión real de la diáspora venezolana, a causa de una multiplicidad de elementos que impiden tener una perspectiva clara de este fenómeno, no puede ser plenamente dimensionada en

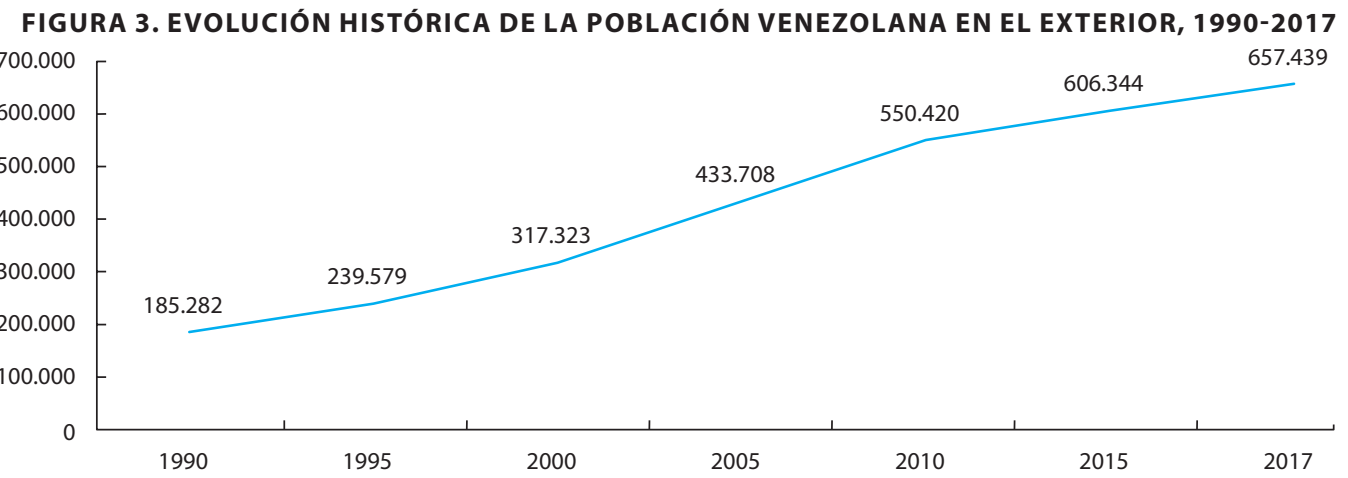

Fuente: elaboración propia basada en información de la Organización de las Naciones Unidas (2017). 
TABLA 6. NÚMERO DE VENEZOLANOS RESIDENTES EN COLOMBIA, 1990-2018

\begin{tabular}{|c|c|c|c|c|c|c|c|}
\hline \multirow{2}{*}{ Venezuela } & 1990 & 1995 & 2000 & 2005 & 2010 & 2015 \\
\cline { 2 - 7 } & 33.123 & 35.162 & 37.200 & 37.137 & 43.511 & 46.614 \\
\hline
\end{tabular}

* La cifra de 2018 corresponde a los datos obtenidos del Registro Administrativo de Migrantes Venezolanos (Gobierno de Colombia, 2018).

Fuente: elaboración propia basada en información de la Organización de las Naciones Unidas (2017).

la actualidad. Además, gran parte de la población venezolana en Colombia obedece a una tendencia migratoria flotante que tiende a moverse en la frontera, el $34 \%$ desarrollan patrones de movimiento transfronterizo de corta duración de forma pendular, y el 66\% de tránsito con miras a desplazarse hacia otros países como Panamá, Ecuador, Perú, Chile, Argentina y Estados Unidos (Migración Colombia, 2018, p. 7).

De acuerdo con Santana (2009) (mapa 2), la dispersión territorial de la migración venezolana en Colombia se asentaba principalmente en la región fronteriza con el Táchira venezolano, al igual que una presencia disgregada en la región Caribe y en las grandes urbes del país. Se destaca la presencia de venezolanos en los departamentos de Norte de Santander (8.303), Distrito Capital de Bogotá (4.578), Atlántico (3.984), y Bolívar (3.898), además de contar con una presencia relevante en el Valle del Cauca (2.664), y en los departamentos de Antioquia (2.655), Santander (2.283), Magdalena (1.369), Sucre (1.290) y Córdoba (1.219). No obstante, si comparamos estos registros con los nuevos referentes estadísticos aportados por el Registro Administrativo de Migrantes Venezolanos (RAMv) (2018), es posible evidenciar que el fenómeno migratorio venezolano mutó de estar en una dimensión fronteriza, a ser una población de profundo impacto a lo largo de la geografía nacional, sin mencionar un incre- mento exponencial del número de venezolanos en Colombia, el cual registra 442.462 personas para 2018, cifra histórica en los registros migratorios. Dentro de la nueva configuración (Gobierno de Colombia, 2018) (mapa 3), aunque se mantiene una fuerte presencia de venezolanos en departamentos fronterizos como Norte del Santander (82.286) y La Guajira (74.874), se resalta una presencia de mayor calado en departamentos de gran peso demográfico como Atlántico (42.771), Bogotá (43.483), Antioquia (21.850) y Valle del Cauca (16.572); niveles que superan ampliamente a los registros anteriores.

Ahora bien, si se realiza un estudio detallado de la evolución de nuevas tendencias migratorias en Colombia, se parte de la desventaja de la carencia estadística sobre este tema, y también de la irregularidad migratoria a causa de la porosidad de la frontera colombo-venezolana. Además de la existencia de un periodo de trece años sin una actualización censal, no hay bases estadísticas para la revisión de las evoluciones de las migraciones extranjeras en Colombia en cifras oficiales; asimismo, no existe una política migratoria integral y actualizada a las nuevas realidades migratorias del mundo y de Colombia como Estado que ha venido presentando un cambio de rol estratégico para los flujos migratorios, del tránsito a la recepción. Sin embargo, metodológicamente es posible realizar una revisión desde la evolución del vo- 
lumen de flujos migratorios de entrada al país, la cual puede ser una herramienta bastante importante para comprender de forma dinámica la evolución de este fenómeno durante los últimos diez años.

Por ejemplo, de acuerdo con registros de la Unidad Administrativa Especial Migración Colombia (2017), una parte considerable de los flujos migratorios de entrada de venezolanos se registraron por vía terrestre; cifras que han percibido incrementos sensibles durante los últimos cinco años. De acuerdo con registros de esta Unidad (tabla 7), el número de venezolanos entrantes al país ha experimentado crecimientos considerables; el Puente Internacional Simón Bolívar en Cúcuta pasó de registrar 39.593 entradas de venezolanos para 2013, a percibir 98.199 en 2016, lo cual significa un crecimiento de $148 \%$ en un lapso de cuatro años.
Asimismo, los puestos fronterizos de Paraguachón y Arauca registraron aumentos relevantes, el primero percibió un incremento del $54 \%$ entre 2013 y 2016, mientras que el segundo registró un alarmante aumento del 903\% para el mismo periodo (tabla 7). Los anteriores registros migratorios demuestran una dimensión masiva de la diáspora venezolana al exterior, especialmente de la población de este país con interés de entrar a territorio colombiano. No obstante, lo novedoso del caso es que, debido a las condiciones críticas de emergencia política y social dentro de la coyuntura política de Venezuela, las tendencias dan visos de que estas poblaciones tienden a ser nuevos migrantes sin un proceso completo de regularización documental. Por ejemplo, los registros de Migración Colombia (2017) (tabla 8) señalan un progresivo decrecimiento del número de entradas de venezolanos con

TABLA 7. EVOLUCIÓN DE LOS FLUJOS MIGRATORIOS DE ENTRADA DE VENEZOLANOS A COLOMBIA POR PUESTOS DE CONTROL FRONTERIZO, 2007-2017

\begin{tabular}{|c|c|c|c|c|c|c|c|c|c|c|c|}
\hline & 2007 & 2008 & 2009 & 2010 & 2011 & 2012 & 2013 & 2014 & 2015 & 2016 & 2017 \\
\hline $\begin{array}{l}\text { Puente Inter- } \\
\text { nacional Simón } \\
\text { Bolívar }\end{array}$ & 43.672 & 62.420 & 47.886 & 49.150 & 49.915 & 40.423 & 39.593 & 60.842 & 68.066 & 98.212 & 421.467 \\
\hline $\begin{array}{l}\text { Puesto Migratorio } \\
\text { de Arauca }\end{array}$ & 304 & 1.446 & 1.310 & 1.301 & 1.556 & 1.643 & 2.250 & 2.759 & 3.175 & 22.578 & 4.516 \\
\hline $\begin{array}{l}\text { Puesto Migratorio } \\
\text { de Paraguachón }\end{array}$ & 34.085 & 38.997 & 38.468 & 38.972 & 36.128 & 45.812 & 41.453 & 45.652 & 43.608 & 64.008 & 152.616 \\
\hline $\begin{array}{l}\text { Puesto Migratorio } \\
\text { Puerto Santander }\end{array}$ & - & - & - & - & - & - & - & - & - & - & 13.832 \\
\hline $\begin{array}{l}\text { PCMF de Puerto } \\
\text { Carreño }\end{array}$ & - & - & - & - & - & 1.147 & 3.342 & 3.588 & 6.941 & 14.084 & 3.666 \\
\hline $\begin{array}{l}\text { PCMF de Puerto } \\
\text { Inírida }\end{array}$ & - & - & - & - & - & - & - & - & 653 & 664 & 872 \\
\hline
\end{tabular}

Fuente: elaboración propia basada en información otorgada por la Unidad Administrativa Especial Migración Colombia, vía derechos de petición, otorgados el 20 de noviembre de 2015 y el 18 de julio de 2018. 
TABLA 8. EVOLUCIÓN DE LOS FLUJOS MIGRATORIOS DE ENTRADA DE VENEZOLANOS A COLOMBIA POR DECLARACIÓN DE RESIDENCIA EN EL EXTERIOR, POR MOTIVOS DE ESTUDIO Y CON VISADO TEMPORAL DE TRABAJO, 2007-2015

\begin{tabular}{|l|c|c|c|c|c|c|c|c|c|c|c|}
\hline & 2007 & 2008 & 2009 & 2010 & 2011 & 2012 & 2013 & 2014 & 2015 & 2016 & 2017 \\
\hline $\begin{array}{l}\text { Venezolanos } \\
\text { con país de } \\
\text { residencia en } \\
\text { el exterior }\end{array}$ & 5.596 & 7.430 & 7.819 & 8.024 & 10.249 & 12.982 & 12.912 & 8.454 & 9.221 & 9.681 & - \\
\hline $\begin{array}{l}\text { Venezolanos } \\
\text { por motivos } \\
\text { de estudio }\end{array}$ & 966 & 1.474 & 1.970 & 1.893 & 2.187 & 2.432 & 2.336 & 2.358 & 2.027 & 2.170 & 818 \\
\hline $\begin{array}{l}\text { Venezolanos } \\
\text { con visado } \\
\text { temporal de } \\
\text { trabajo }\end{array}$ & 3.080 & 4.310 & 4.946 & 6.083 & 8.959 & 11.296 & 11.705 & 10.446 & 8.937 & 7.562 & 2.806 \\
\hline
\end{tabular}

Fuente: elaboración propia basada en información otorgada por la Unidad Administrativa Especial Migración Colombia, vía derecho de petición, otorgada el 20 de noviembre de 2015.

visado temporal de trabajo, en el que se pasó de percibir un pico de 11.296 entradas para 2012, a registrar solamente 2.806 movimientos de entrada de personas con visado temporal para 2017.

Otro indicio del fenómeno de la población venezolana sin experiencia previa de migración se puede observar en los flujos de personas con residencia fuera de Venezuela y los flujos por concepto de estudios. De acuerdo con la tabla 8 , se pasó de registrar 12.982 venezolanos entrantes a Colombia con residencia en el exterior y 2.432 venezolanos entrantes por concepto de estudios para 2012, a 9.681 venezolanos residentes en el extranjero para 2016, y solamente 818 venezolanos por concepto de estudios.

Lo anterior refleja, no solamente la existencia de nuevos migrantes dentro de la diáspora venezolana en Colombia, sino también puede interpretarse como un fenómeno de "encarecimiento" de la decisión de emigrar hacia otro país. El deterioro del tipo de cambio del bolívar venezolano ha generado una reducción de la capacidad de compra y gasto del migrante en el exterior. A pesar de la existencia de sistemas de control estatal del tipo de cambio y de las divisas, la escasez de divisas ha provocado el surgimiento de un mercado paralelo que, paulatinamente, ha dificultado el acceso de los venezolanos a los medios necesarios para migrar. Sin embargo, el estudio de estos fenómenos representa una temática demasiado amplia como para ser abordada plenamente en este trabajo.

Para finalizar, es necesario comprender que todas estas nuevas tendencias de migración son elementos que nos permiten argumentar la seria relevancia del presente escenario en frontera. Teniendo en cuenta que todos estos elementos que han configurado una nueva forma de migración dentro de la región, el desarrollo de una política de Estado concisa, basada en los principios de la acción humanita- 
ria, la cooperación bilateral y el apoyo internacional para garantizar un espacio de seguridad humana en la frontera, es de vital importancia revisar las iniciativas desarrolladas para la consolidación de una gobernabilidad en las zonas de frontera; zonas que pueden convertirse en grandes oportunidades o amenazas de corte económico, social y político.

\section{PROCESOS DE REGULARIZACIÓN Y CONTROL DE TRÁNSITO DE MIGRANTES A TRAVÉS DE LA FRONTERA COLOMBO- VENEZOLANA}

La frontera colombo-venezolana se extiende por más de $2.200 \mathrm{~km}$, y delimita los departamentos de La Guajira, Cesar, Boyacá, Norte de Santander, Arauca, Vichada y Guainía, del lado colombiano de la frontera, y Zulia, Táchira, Apure y Amazonas como estados fronterizos venezolanos. Esta frontera, cuenta con siete pasos fronterizos autorizados, tanto terrestres como fluviales, estos son: los puentes internacionales Francisco de Paula Santander, Simón Bolívar y La Unión, en Cúcuta; el Puente Internacional José Antonio Páez en Arauca; el paso en Paraguachón, La Guajira; y los muelles de los ríos Inírida-Guaviare-Atabapo en Guainía y Orinoco en Puerto Carreño, Vichada (mapa 4).

A través de los años, esta frontera ha tenido diferentes retos para los dos países en términos de gobernabilidad, control y regularización del paso de nacionales tanto colombianos como venezolanos hacia ambos lados; esto teniendo en cuenta las grandes asimetrías económicas que se plantean en estos territorios.
Los últimos diez ańos han sido una época llena de cambios y de desarrollo de diferentes políticas, acuerdos, comisiones para regularizar la situación en la frontera. En 2011, teniendo en cuenta "la inexistencia de una política integral para las fronteras y una oferta institucional que reconozca sus características y realidades" (Cancillería, 2013, p. 1), el Gobierno colombiano diseñó el Plan Fronteras para la Prosperidad, sustentado en el Plan Nacional de Desarrollo. A través de este:

... se destaca la necesidad de construir una política pública diferencial para las zonas de frontera del país que siente las bases para el desarrollo de estas regiones de Colombia [...] buscando mejorar la capacidad institucional, respondiendo de manera estratégica, integral, adecuada y oportuna a los retos que se presentan diariamente en las regiones fronterizas (Cancillería, 2013, p. 3).

Para el desarrollo de este plan, en el área fronteriza con Venezuela se logró la identificación de seis subregiones de frontera: Alta Guajira, Serranía de Perijá, Catatumbo, Andina, Orinoquia, Amazonia. Este mismo año, a través del Decreto 4062 del 2011, se creó la Unidad Administrativa Especial Migración Colombia, un "organismo técnico especializado encargado de ejercer las funciones de autoridad de vigilancia y control migratorio del Estado colombiano [...] y de extranjería” (Departamento Administrativo de la Función Pública, 2011). Migración Colombia es la entidad encargada de generar un apoyo al Ministerio de Relaciones Exteriores para:

... la formulación y ejecución de la política migratoria, [...] llevar el registro e identificación de extranjeros, 
[...] la verificación de su estatus migratorio, [...] expedición de documentos como cedulas de extranjería, salvoconductos, $[\ldots]$ trámites y documentos derivados [...], formular, dirigir, coordinar y evaluar los planes, programas y proyectos en materia de control migratorio, extranjería y verificación migratoria, en desarrollo y de conformidad con la política migratoria (Departamento Administrativo de la Función Pública, 2011).

Para este año, esta frontera contaba con cuatro pasos habilitados para el tránsito entre los dos países: Paraguachón (La Guajira), los puentes Simón Bolívar (Norte de Santander) y José Antonio Páez (Arauca), y los muelles de Puerto Carreño (Vichada) e Inírida (Guainía) (Migracion Colombia, 2017). En los años posteriores, se dio paso a la apertura de los otros pasos fronterizos, los cuales han servido como espacios de control y registro del flujo de salida y entrada de colombianos y venezolanos al país.

Por otro lado, en el año 2001 se creó la Comisión Intersectorial de Integración y Desarrollo Fronterizo (CIIDEF), "órgano articulador interinstitucional en función del desarrollo fronterizo, [...] encargado de ejercer la coordinación, orientación superior y consolidación de la política de Estado relativa a la integración y el desarrollo fronterizo" (Cancillería, 2011). Más adelante, en 2014, se llevó a cabo la primera sesión de la CIIDEF, la cual dio como resultado la identificación de los lineamientos, entre los cuales se encuentran:

a) Apoyar la estructuración de proyectos de impacto regional. b) establecer un sistema de incentivos a la gestión territorial. c) desarrollar una estrategia articulada para asistencia técnica y acompańamiento a entidades territoriales, a partir de la formulación de un modelo de gestión territorial, integral y diferenciado. d) fortalecer la capacidad institucional y técnica de las entidades del Gobierno nacional para formular y ejecutar políticas públicas integrales de enfoque territorial. e) mejorar los procesos e instrumentos de control a la gestión (Aparicio, Rodríguez y Tamara, 2016, p. 54).

En este mismo año, en agosto del 2014, se dio por primera vez un cierre de la frontera, con la intención de reducir el contrabando entre los dos países. En este mes se crea el Centro Binacional de Comando y Control contra el Contrabando (СЕвоc), con sedes en San Cristóbal y Cúcuta, ciudades de Venezuela y Colombia respectivamente. Este Centro dio como resultado, en el transcurso de un año, el desmantelamiento de 21 estructuras dedicadas al contrabando, entre las cuales cinco actuaban a nivel binacional, y al mejoramiento en un $30 \%$ de las acciones contra el contrabando (Delgado, 2016, p. 149). Sin embargo, el 19 de agosto del 2015, un año después de la creación del севос, el presidente de Venezuela Nicolás Maduro:

... ordenó el cierre de la frontera, en seis municipios del estado Táchira. Progresivamente se cerraron otros pasos fronterizos hasta el 3 de octubre, fecha en que se reportó el cierre total de la frontera entre Colombia y Venezuela. [...] Esta decisión se ha tomado debido a un ataque armado contra militares venezolanos y un civil, ataque que fue atribuido a supuestos paramilitares colombianos. Además, Venezuela denuncia el contrabando y la criminalidad que existe en la zona fronteriza. Estas medidas llevaron a la expulsión directa e inmediata de 1.950 colombianos indocumentados que vivían en Venezuela [...] Entre el 21 de agosto y el 22 de septiembre (fecha oficial de cierre del registro) se reportan 22.302 
personas que han regresado a Colombia a través de puntos fronterizos informales (Clúster de Protección - Colombia, 2015).

Mediante la activación del estado de excepción en los estados federales fronterizos de Zulia, Táchira, Apure y Amazonas, se buscó restablecer el orden público por hipotéticas incursiones paramilitares en Venezuela desde territorio colombiano, lo cual forzó los mencionados escenarios de deportación que marcaron el inicio de una nueva fase en el desarrollo de las formas de interacción bilateral en la región de frontera. En este sentido, se evidencia que las dinámicas de los pasos fronterizos entre ambos países, y, con esto las políticas públicas y reacciones de política exterior de cada uno de los Estados se basan en abordajes y manejos diferentes, "mientras que el Estado colombiano lee la frontera como una zona importante en términos de desarrollo económico -y con componentes importantes de gasto social-, el Estado venezolano entiende la franja limítrofe en términos de seguridad nacional" (Rodríguez e Ito, 2016, p. 174). Por ende, respecto al tema migratorio, es posible interpretar esta disparidad como un espacio que complica el desarrollo de una cooperación fluida para el manejo y monitoreo de los movimientos regulares e irregulares, lo cual conduce a procesos de percepción de amenaza y su tipificación como un asunto de seguridad.

Es importante recalcar que "pese al cierre de la frontera decretado por el Gobierno venezolano, durante el año 2015, la Unidad Administrativa Especial Migración Colombia registro la entrada al territorio nacional de 329.478 ciudadanos venezolanos y la salida de
314.666 nacionales de este país" (Migracion Colombia, 2017). Como respuesta a los crecientes retos que se venían presentando en el manejo de las fronteras, en julio 2016 el Gobierno de Colombia decidió la creación de la Tarjeta Migratoria de Tránsito Fronterizo, la cual comenzó a funcionar el 13 de agosto de 2016, momento en el que el presidente Maduro decide la reapertura del paso fronterizo en horario restringido. Adicionalmente, Migración Colombia decide la apertura de los dos más recientes puestos de control migratorio en la frontera colombo-venezolana. Es importante resaltar que el porte de la Tarjeta Migratoria de Tránsito Fronterizo da la posibilidad de ingreso únicamente hasta los cascos urbanos de la ciudad fronteriza más cercana, y que, en caso de querer dirigirse a cualquier otro punto del país, los venezolanos deben presentar su pasaporte.

Más adelante, en febrero del 2017, este documento fue reemplazado por la Tarjeta de Movilidad Fronteriza (TMF). La TMF era únicamente para ciudadanos venezolanos que habitaran en 23 zonas de 5 estados de Venezuela (Amazonas, Zulia, Apure, Bolívar y Táchira). Este documento tendría dos fases: una etapa de prerregistro con una vigencia inicial de 6 meses, y una vigencia de 3 años después del momento de la expedición de la TMF. Adicionalmente, en julio del 2017, la Cancillería y Migración Colombia anunciaron la creación de un Permiso Especial de Permanencia (PEP), el cual busca regularizar la situación migratoria de los venezolanos que, pese a habérseles vencido el plazo del Permiso Temporal de Permanencia (PTP), no han abandonado el territorio nacional. Este documento tiene una vigencia 
de 90 días prorrogables automáticamente hasta completar dos años.

Sin embargo, ante la creciente población de venezolanos en Colombia, en un escenario de desentendimiento diplomático bilateral con las autoridades venezolanas, surge la necesidad de implementar otro mecanismo de monitoreo. Con miras a complementar los registros migratorios avanzados por Migración Colombia, además de generar un insumo estadístico para la formulación de políticas públicas integrales para la atención humanitaria bajo mandato del Decreto 542 de 2018, se crea el Registro Administrativo de Migrantes Venezolanos (RAMv). Dicho registro abarca un trabajo mancomunado interinstitucional entre la Unidad Nacional para la Gestión del Riesgo de Desastres (UngRD), la Defensoría del Pueblo, la Federación Nacional de Personeros (FENALPER) y el Gobierno de Colombia, con apoyo de la Organización Internacional para las Migraciones (OIM), la Agencia de los Estados Unidos para el Desarrollo Internacional (UsAid), y el Alto Comisionado de las Naciones Unidas para los Refugiados (ACNUR). Dicha iniciativa se ejecutó a lo largo de dos meses, entre abril y junio de 2018, con miras a dar un registro ampliado a venezolanos que "no tengan ningún registro vigente en colombia; es decir que no tengan cédula de extranjería, una visa de permanencia, Permiso de Ingreso y Permanencia (PIP) o el Permiso Especial de Permanencia (PEP) vigente, aunque los que tengan la TMF también deben [hacer] el registro" (Unidad Nacional para la Gestión del Riesgo de Desastres, 2018).

Dado que esta es una iniciativa interinstitucional para dar respuesta inmediata, como una medida estadística complementaria para reducir el subregistro migratorio en el país se instalaron 1.019 puntos de registro en 413 municipios de 30 departamentos, salvo Vaupés y San Andrés y Providencia. Como resultado de esta campaña, se estableció un proceso de registro que arrojó las cifras expuestas en la tabla 6 (mapa 3). Aunque la iniciativa fue un gran aporte estadístico basado en un esfuerzo sinérgico entre diversas instituciones para atender un problema de alta contingencia, no da una solución al estatus migratorio de quienes se registran, lo cual muestra una desarticulación con los demás procesos instalados sobre el tema.

Lo anterior deja en entrevisto los diferentes esfuerzos que se han hecho en los últimos años para regularizar y controlar los flujos de entrada y salida de migrantes a través de los puestos de control fronterizo, y, sumado a esto, los esfuerzos que se han hecho por parte del Gobierno colombiano para proyectar las fronteras como "zona de desarrollo económico y de demandas sociales que requieren especial atención de parte de las autoridades nacionales y de los gobiernos regionales y locales, generando políticas públicas para efectuar un 'cierre de brechas' en términos intrarregionales como interregionales" (Rodríguez e Ito, 2016, p. 178). Dichos esfuerzos han traído un relativo éxito, puesto que han buscado responder de una forma organizada a una problemática migratoria con alto riesgo de padecer de subregistros, irregularidad y, por ende, ilegalidad. No obstante, la presencia de un fenómeno migratorio sin precedentes en la historia nacional ha puesto en evidencia la carencia de capacidad de reacción coordinada que, ante la inminencia 
de un problema social de una coyuntura política tan próxima, denota un cierto recelo del Estado colombiano sobre cualquier proceso desarrollado en zona fronteriza.

No obstante, durante los últimos diez años el tema de la porosidad de la frontera colombo-venezolana ha incidido directamente en los diversos escenarios de ilegalidad que han prosperado en esta zona, tales como la presencia de grupos armados al margen de la ley, además de la transformación misma del fenómeno del narcotráfico, del contrabando, del tráfico de migrantes y de la creciente desconfianza política que se ha dado como resultado de los proyectos políticos divergentes que se desarrollaron en los escenarios internos de ambos países. A pesar del crónico estado de crisis económica y política en Venezuela, dentro del cual no existe una definición clara de roles y responsabilidades sobre los elementos críticos de la frontera por parte de los Estados colombiano y venezolano, los escenarios de crisis en las relaciones bilaterales han estado vigentes durante los últimos años; desencuentros que han repercutido nocivamente en el desarrollo de una agenda de cooperación y lucha conjunta.

Por tanto, dentro de este largo proceso, el flujo de migraciones en la frontera colombovenezolana, al ser un fenómeno relativamente reciente, se ha ido desarrollando de manera paralela con las dinámicas y transformaciones políticas, económicas y sociales de ambos países, en las que se han consolidado redes sociales de migrantes condicionadas por factores de atracción y expulsión contextuales que determinan e influyen en la realización de movimientos migratorios, ya sean de salida o de retorno. Asimismo, las migraciones son un fenómeno que se desarrolla en el marco de una región marcada por la violencia, el narcotráfico, el contrabando y el drama humanitario, lo cual incide directamente en la responsabilidad compartida de Colombia y Venezuela por la preservación de una cooperación bilateral fluida y saludable para la protección de esta zona de frontera.

\section{CONCLUSIONES}

El escritor venezolano Arturo Uslar Pietri acunó el concepto de "tercer país" para hacer referencia a la realidad de la frontera colombovenezolana, entendida esta como una región de límites difusos que, debido a su histórica interacción bilateral, se ha convertido en una relativa unidad. Dicha región demuestra una gran diversidad de elementos geográficos, políticos, económicos y sociales que han determinado un escenario político de alta complejidad para su comprensión. Sin embargo, a partir de dicho contexto, se ha hecho ineluctable la necesidad de construir una política pública diferencial para las zonas de frontera del país, que siente las bases para el desarrollo de estas regiones de Colombia. No obstante, a partir de una progresiva coyuntura de tensión diplomática y política, la desconfianza política que se ha dado como resultado de los proyectos políticos divergentes que se desarrollaron en los escenarios internos de ambos países ha complicado una correcta lectura de la situación fronteriza entre Colombia y Venezuela.

La turbulenta crisis política y económica en Venezuela ha impulsado el desarrollo 
masivo de una diáspora con proporciones sin precedentes durante los últimos diez años, a pesar de ser históricamente un país receptor de migrantes. Asimismo, a pesar de que la diáspora colombiana en Venezuela en los últimos veinte ańos se ha caracterizado por ser dominante en la representación porcentual del total de la población extranjera en este país, las condiciones de crisis económica y política han incidido directamente en el decrecimiento de las migraciones hacia este destino, tanto en el desarrollo mismo de las migraciones laborales y estudiantiles como en su distribución territorial y volumen de envío de remesas.

No obstante, a pesar de la emergencia que ha suscitado la entrada masiva de venezolanos en Colombia, esta situación ha reflejado en un nuevo nivel la gran vulnerabilidad y riesgo que engloba un escenario de debilidad institucional, de falta de gobernabilidad, de inseguridad y de abandono que puede incidir directamente en el manejo adecuado de una política de fronteras. Por tanto, en el marco de una política de Estado basada en los principios de la acción humanitaria, la cooperación bilateral y el apoyo internacional para garantizar un espacio de seguridad humana en la frontera es de vital importancia revisar las iniciativas desarrolladas para la consolidación de una gobernabilidad en estas zonas, las cuales pueden determinar grandes oportunidades o amenazas de corte económico, social y político. Por esto, no solo es importante fortalecer la frontera como un espacio de cooperación, paz y amistad entre diversas naciones, sino que también debe ser una tierra propia de sus habitantes, en la que la libertad, la democracia y la fraternidad sean la más fuerte de las barreras contra la muerte, la violencia y la represión.

\section{REFERENCIAS}

Abel, C. y Palacios, M. (1991). Colombia, 1930-1958.

En L. Bethell (ed.), Historia de América Latina. Los paises andinos desde 1930 (t. Xvi: pp. 173207). Barcelona: Crítica.

Abel, C. y Palacios, M. (1991). Colombia, 1958-1990.

En L. Bethell (ed.), Historia de América Latina. Los paises andinos desde 1930 (t. Xvi: pp. 208258). Barcelona: Crítica.

Alto Comisionado de las Naciones Unidas para los Refugiados (ACNUR) (2016a). Population Statistics Database. Recuperado de: http://goo.gl/YZnXpz

Alto Comisionado de las Naciones Unidas para los Refugiados (ACNUR) (2016b). Mid-year Statistics - 2015. Recuperado de: http://goo.gl/YZnXpz

Aparicio, C. A., Rodríguez, K. y Tamara, P. (2016). Descripción y contextualización de la política de fronteras. En A. Molano-Rojas, Fronteras en Colombia como zonas estratégicas: análisis y perspectivas (pp. 47-68). Bogotá: Ediciones Antropos.

Arráiz Lucca, R. (2007. Venezuela: 1830 a nuestros dias - Breve historia politica (pp. 159-223). Caracas: Editorial Alfa.

Banco de la República (2016). Bases de datos sobre ingresos de remesas por pais de origen. Recuperado de http://goo.gl/WLmq5b

Cabrera, I. (23 de marzo de 2011). Fronteras en medio de conflictos prolongados: análisis a partir de los casos de Afganistán, Colombia y República Democrática del Congo. Ponencia para el XXIII Congreso Internacional de la Asociación 
Latinoamericana de Estudios de Asia y África (ALADAA). Recuperado de https://bit.ly/2AvdjEc.

Cancillería (2011). Comisión Intersectorial de Integración y Desarrollo Fronterizo (CIIDEF). Recuperado de http://bit.ly/2FWaUQA

Cancillería (2013). Plan Fronteras para la Prosperidad: Resumen ejecutivo proyecto de inversión 2013. Recuperado de http://bit.ly/1HdHKqM

Cárdenas, M. y Mejía, C. (2006). Migraciones Internacionales en Colombia: ¿qué sabemos?. Working Papers Series, 30. Fedesarrollo. Recuperado de http://goo.gl/ifx1GY

Clúster de Protección - Colombia (23 de octubre de 2015). Situación en la frontera ColombiaVenezuela: vacios de protección y recomendaciones. Recuperado de http://bit.ly/2C6kIFp

Comisión Económica para América Latina y el Caribe (CEPAL) (2016). Investigación de la Migración Internacional en Latinoamérica (IMILA). [Bases de datos de censos para países latinoamericanos y del Caribe]. Recuperado de http://goo. $\mathrm{gl} / \mathrm{RkVkLf}$

Consultores 21 (2017). Servicio de análisis de entorno: análisis sobre migración, 151 del cuarto trimestre. Recuperado de: https://bit.ly/2N9FA4Z.

Deas, M. (1991). Venezuela, Colombia y Ecuador. En L. Bethell (ed.), Historia de América Latina. América Latina Independiente 1820-1870 (t. vI, pp. 259-300). Barcelona: Crítica.

Delgado, J. (2016). Los desafíos de seguridad en la frontera. En A. Molano-Rojas, Fronteras en Colombia como zonas estratégicas: análisis y perspectivas (pp. 145-165). Bogotá: Ediciones Antropos.

Departamento Administrativo de la Función Pública (31 de octubre de 2011). Decreto 4062 del 2011. Recuperado de http://bit.ly/1LWVWMi
Departamento Nacional de Planeación (2014). Implementación de la Politica de Fronteras. Recuperado de http://bit.ly/2C72MdR

Echandía, C. (2000). El conflicto armado colombiano en los ańos noventa: cambios en las estrategias y efectos económicos. Revista Colombia Internacional - Universidad de los Andes, (49-50), pp. 117-134.

El Tiempo (19 de enero de 2018). Las razones que han llevado a los venezolanos a migrar a Colombia. Recuperado de https://goo.gl/W5P374

Ewell, J. (1991). Venezuela: 1930-1990. En L. Bethell, Historia de América Latina. Los paises andinos desde 1930 (t. xvi, pp. 301-356). Barcelona: Crítica,

Gobierno de Colombia, et al. (2018). Informe FinalRegistro Administrativo de Migrantes Venezolanos. Recuperado de https://bit.ly/2v1merJ

Grupo Académico Colombia-Venezuela (2015). Flujo migratorio de colombianos a Venezuela: las cifras cuentan. Recuperado de http://goo.gl/yJOVw4

Instituto Nacional de Estadística - Venezuela. 2014. xIV Censo Nacional de Población y Vivienda. Recuperado de http://goo.gl/KULTe4

Márquez, J. y Mayansky, A. (1980). Migraciones laborales, sistemas de seguridad social y migración colombo-venezolana, 12 (pp. 7-16). Bogotá: Ministerio de Trabajo y Seguridad Social, SENALDE, PNUD.

Mejía Ochoa, W. (2012). Colombia y las migraciones internacionales. Evolución reciente y panorama actual a partir de las cifras. Revista Internacional de Movilidad Humana, 20 (39), 185-210. Recuperado de http://goo.gl/FMcZY6

Migración Colombia (16 de agosto de 2017). Radiografía de venezolanos en Colombia. Recuperado de http://bit.ly/2BN9mdM 
Organización de las Naciones Unidas (ONU) (2017). Total International Migrant Stock Report. Recuperado de https://goo.gl/2tWzpi

Organización Internacional para las Migraciones (OIM) (2012a). Perfil migratorio de Colombia. Recuperado de http://goo.gl/Kgfk27

Organización Internacional para las Migraciones (OIM) (2012b). Panorama migratorio de América del Sur. Recuperado de https://goo.gl/ckCFh2

Palma, M. (2015). ¿País de emigración, inmigración, tránsito y retorno? La formación de un sistema de migración colombiano. Revista del Observatorio de Análisis de los Sistemas Internacionales, 21 (1), 7-28. Recuperado de http://goo.gl/lasa1U Portafolio (7 de octubre de 2016). Reabren los siete pasos fronterizos entre Colombia y Venezuela. Recuperado de http://bit.ly/2EQyQpq

Rodríguez, R. e Ito, J. C. (2016). La frontera colombovenezolana: dos visiones divergentes. En A. Molano Rojas, Fronteras en Colombia como zonas estratégicas: análisis y perspectivas (pp. 169-183). Bogotá: Ediciones Antropos.
Santana Rivas, D. (2009). Geografía de la inmigración venezolana en Colombia entre 1993 y 2008. Aracne. Revista electrónica de recursos en internet sobre geografía y ciencias sociales, 124. Recuperado de https://goo.gl/C6xpfQ

Scrofina, S. (2012). Los datos del petróleo venezolano. Revista Debates - IESA, 21 (2), 20-23.

Unidad Administrativa Especial Migración Colombia (20 de noviembre de 2015). Respuesta a Derecho de Petición - 20156222558632. Información de acceso público mediante solicitud formal.

Unidad Administrativa Especial Migración Colombia. (2018). Radiografía Migratoria Colombia - Venezuela. Recuperado de https://goo.gl/Mm4Rnn

Unidad Administrativa Especial Migración Colombia (18 de julio de 2018). Respuesta a Derecho de Petición - 20182150485561. Información de acceso público mediante solicitud formal.

Unidad Nacional para la Gestión del Riesgo de Desastres (2018). Registro Administrativo de Migrantes Venezolanos (RAMv). Recuperado de https:// bit.ly/2v5qtTd. 


\section{ANEXOS}

MAPA 1. DISPERSIÓN TERRITORIAL DE COLOMBIANOS EN VENEZUELA, 2011

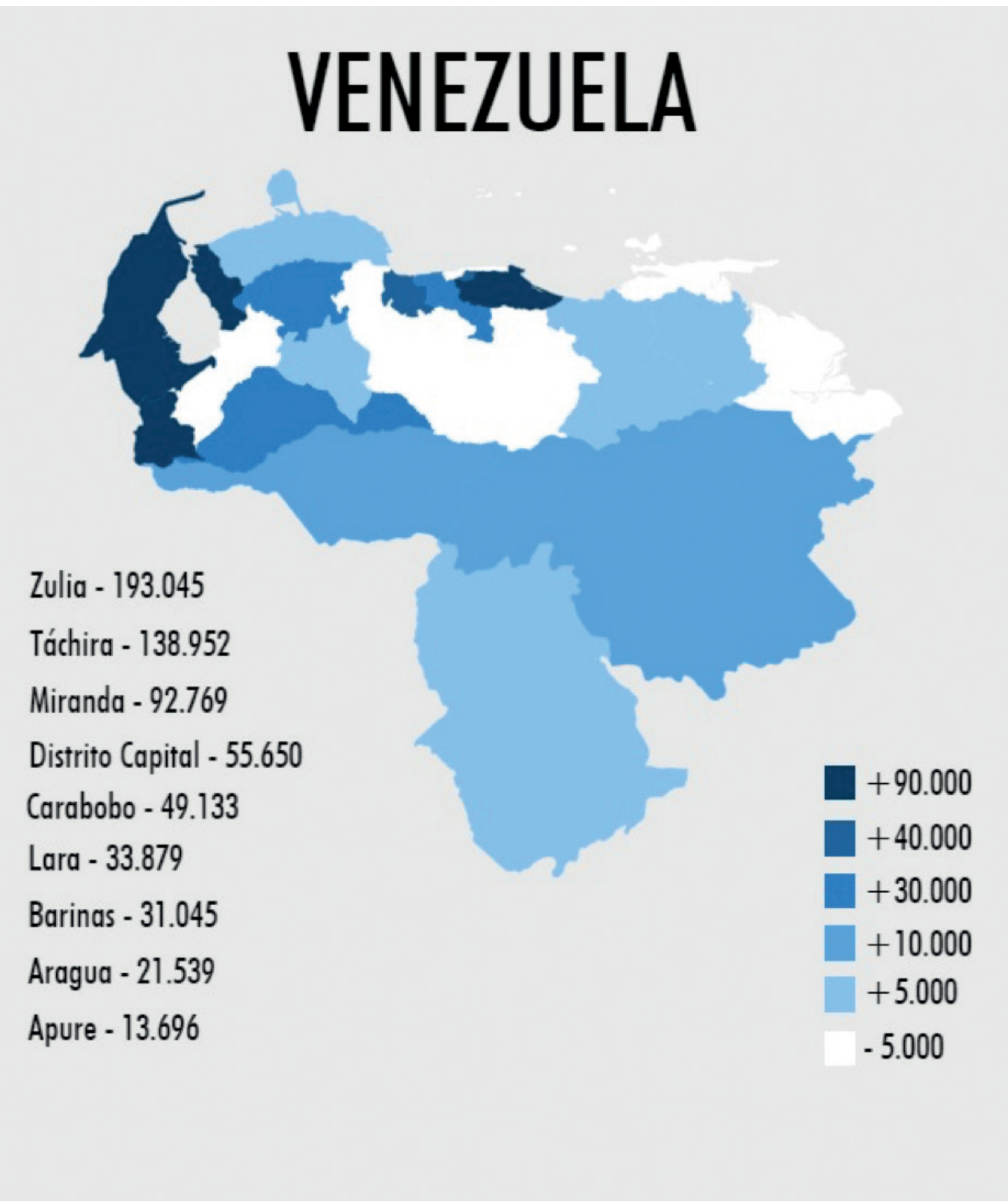


MAPA 2. DISPERSIÓN TERRITORIAL DE VENEZOLANOS EN COLOMBIA, 2009

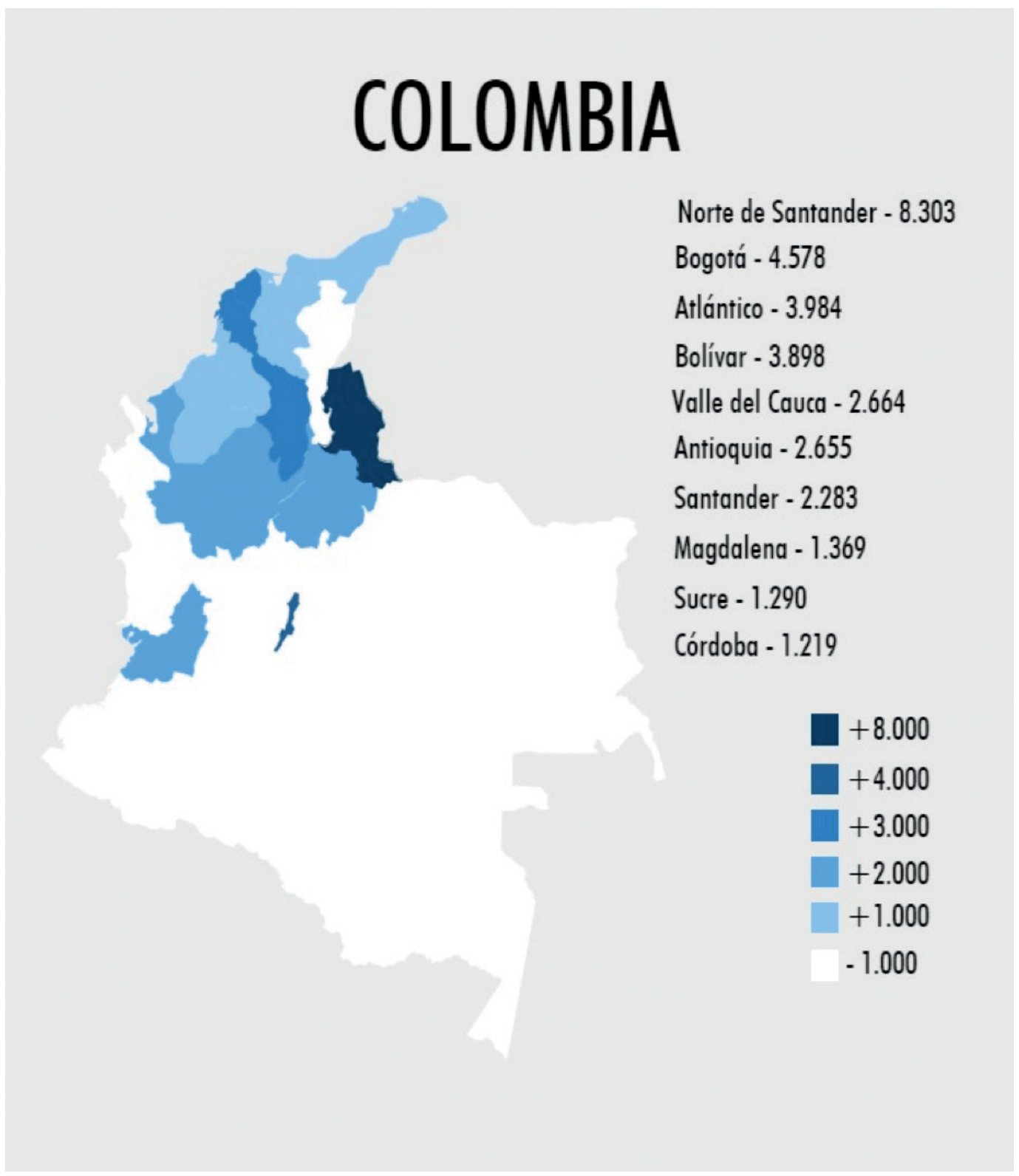

Fuente: adaptación propia basada en información de Santana Rivas (2009). 
MAPA 3. DISPERSIÓN TERRITORIAL DE VENEZOLANOS EN COLOMBIA, 2018

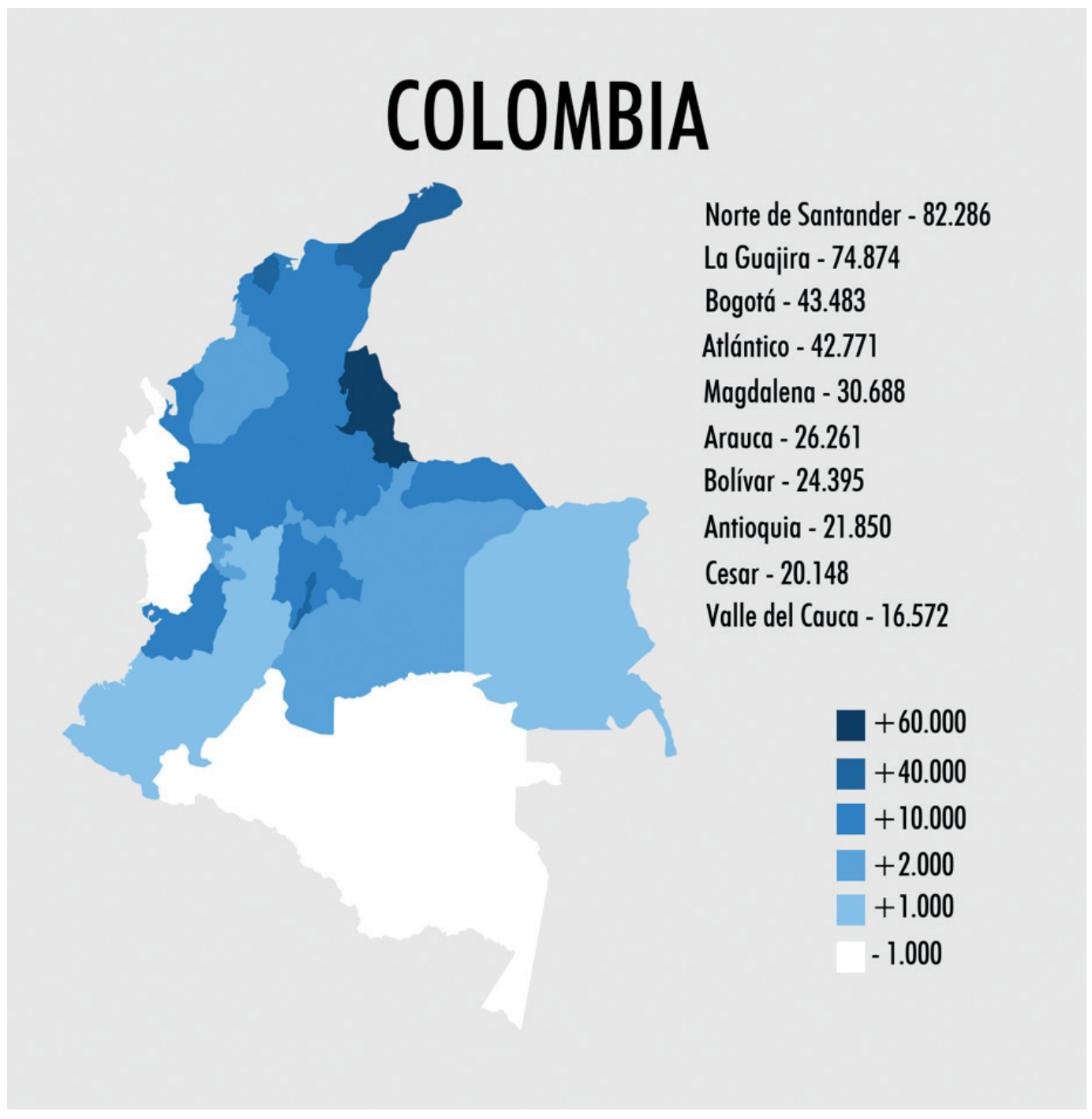

Fuente: adaptación propia basada en información del Registro Administrativo de Migrantes Venezolanos, coordinado por el Gobierno de Colombia (2018). 
MAPA 4. PASOS FRONTERIZOS Y DE CONTROL MIGRATORIO ENTRE COLOMBIA Y VENEZUELA

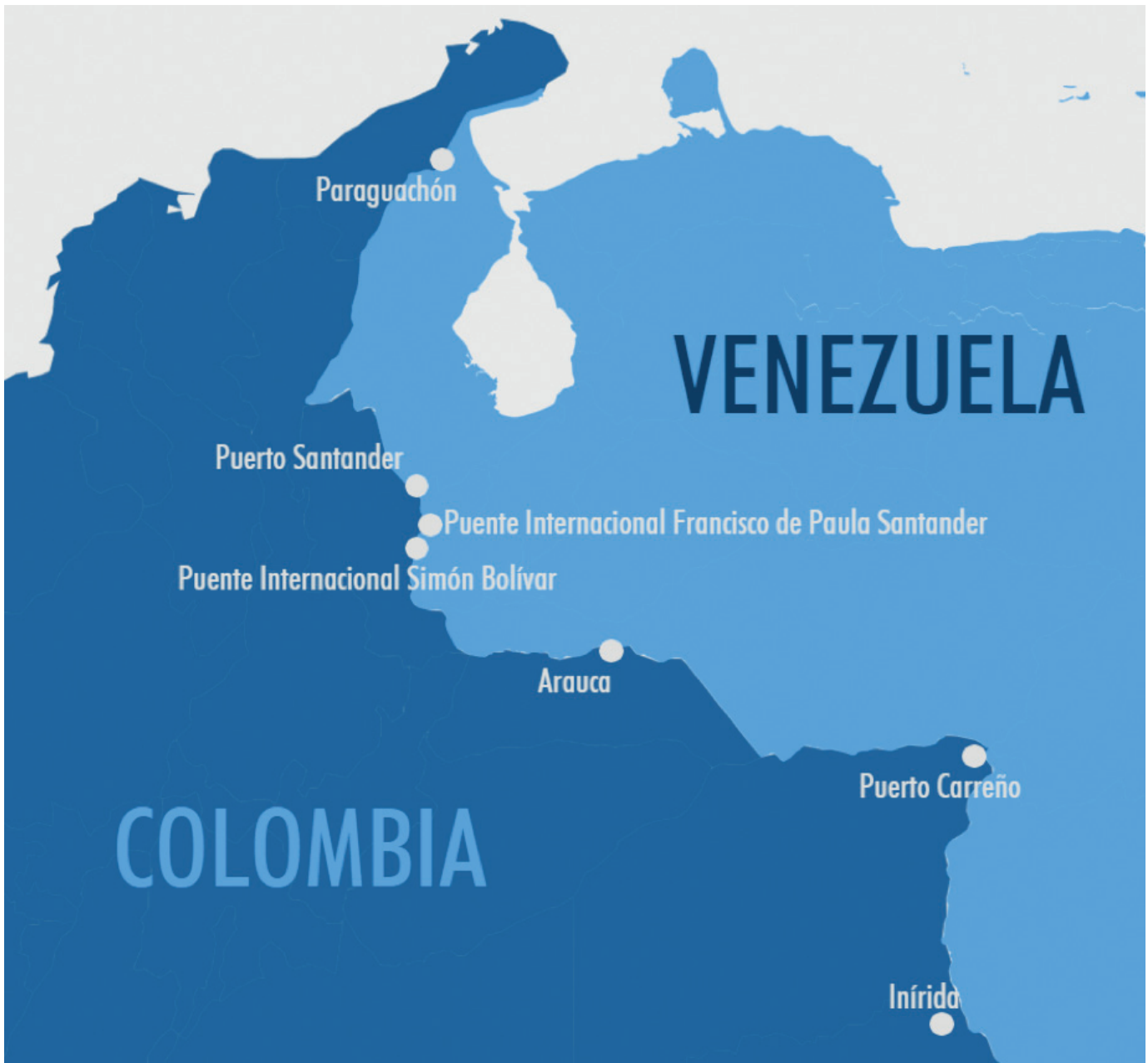

Fuente: adaptación propia basada en información de la Unidad Administrativa Especial Migración Colombia. 